Santa Clara University

Scholar Commons

Civil Engineering

School of Engineering

$2-2013$

\title{
Probabilistic estimates of future changes in California temperature and precipitation usingstatistical and dynamical downscaling
}

David W. Pierce

Tapash Das

Daniel R. Cayan

Edwin P. Maurer

Santa Clara University, emaurer@scu.edu

Norman L. Miller

See next page for additional authors

Follow this and additional works at: https://scholarcommons.scu.edu/ceng

Part of the Civil and Environmental Engineering Commons

\section{Recommended Citation}

Pierce, D.W. T. Das, D.R. Cayan, E.P. Maurer, N. Miller, Y. Bao, M. Kanamitsu, K. Yoshimura, M.A. Snyder, L.C. Sloan, G. Franco, M. Tyree, 2013, Probabilistic estimates of future changes in California temperature and precipitation using statistical and dynamical downscaling, Climate Dynamics 40(3-4):839-856, DOI: 10.1007/s00382-012-1337-9. 


\section{Authors}

David W. Pierce, Tapash Das, Daniel R. Cayan, Edwin P. Maurer, Norman L. Miller, Yan Bao, M. Kanamitsu, Kei Yoshimura, Mark A. Snyder, Lisa C. Sloan, Guido Franco, and Mary Tyree 
1 Probabilistic estimates of future changes in

2 California temperature and precipitation using

3 statistical and dynamical downscaling

4 David W. Pierce,

5 Tapash Das ${ }^{1,6}$

6 Daniel R. Cayan ${ }^{1}$

7 Edwin P. Maurer ${ }^{2}$

8 Norman L Miller ${ }^{3}$

$9 \quad \mathrm{Yan}_{\mathrm{Bao}}^{3}$

10 M. Kanamitsu ${ }^{1}$

11 Kei Yoshimura ${ }^{1}$

12 Mark A. Snyder ${ }^{4}$

13 Lisa C. Sloan ${ }^{4}$

14 Guido Franco 5

15 Mary Tyree $^{1}$

$16{ }^{1}$ Scripps Institution of Oceanography, La Jolla, CA

$17 \quad{ }^{2}$ Santa Clara University, Santa Clara, CA

$18{ }^{3}$ University of California, Berkeley, Berkeley, CA

$19{ }^{4}$ University of California, Santa Cruz, Santa Cruz, CA

$20{ }^{5}$ California Energy Commission, Sacramento, CA

$21{ }^{6}$ CH2M HILL, Inc., San Diego, CA

22 *Corresponding Author address: SIO/CASPO, Mail stop 0224, La Jolla, CA,

23 92093-0224.dpierce@ucsd.edu, 858-534-8276. Fax: 858-534-8561

24 Version 27 February 2012 


\section{ABSTRACT}

26 Sixteen global general circulation models were used to develop probabilistic projections of

27 temperature (T) and precipitation (P) changes over California by the 2060s. The global models

28 were downscaled with two statistical techniques and three nested dynamical regional climate

29 models, although not all global models were downscaled with all techniques. Both monthly and

30 daily timescale changes in $\mathrm{T}$ and $\mathrm{P}$ are addressed, the latter being important for a range of

31 applications in energy use, water management, and agriculture. The $\mathrm{T}$ changes tend to agree more

32 across downscaling techniques than the $\mathrm{P}$ changes. Year-to-year natural internal climate variability

33 is roughly of similar magnitude to the projected $\mathrm{T}$ changes. In the monthly average, July

34 temperatures shift enough that that the hottest July found in any simulation over the historical

35 period becomes a modestly cool July in the future period. Januarys as cold as any found in the

36 historical period are still found in the 2060s, but the median and maximum monthly average

37 temperatures increase notably. Annual and seasonal $\mathrm{P}$ changes are small compared to interannual

38 or intermodel variability. However, the annual change is composed of seasonally varying changes

39 that are themselves much larger, but tend to cancel in the annual mean. Winters show modestly

40 wetter conditions in the North of the state, while spring and autumn show less precipitation. The

41 dynamical downscaling techniques project increasing precipitation in the Southeastern part of the

42 state, which is influenced by the North American monsoon, a feature that is not captured by the

43 statistical downscaling. 


\section{1. Introduction}

45 California has a confluence of factors that make it particularly vulnerable to

46 anthropogenically-induced climate change (e.g., Hayhoe et al. 2004, Cayan et al.

47 2006). Warming and precipitation changes will directly impact crops and pests in

48 the agricultural and wine-producing regions, and affect regional water resources

49 and flood risk through changes in the snow line, snowpack, and

50 evapotranspiration. Indeed, anthropogenic effects can already be seen in the

51 temperature and hydrology of the western U.S. (Barnett et al. 2008, Pierce et al.

52 2008, Bonfils et al. 2008, Hidalgo et al. 2009, Das et al. 2009; cf. Maurer et al.

53 2007, who examined a smaller region).

54 The primary purpose of this work is to present projections of temperature (T) and

55 precipitation $(\mathrm{P})$ change over California by the 2060s in a probabilistic framework

56 (e.g. Manning et al. 2009; Chen et al. 2011), which facilitates risk-based planning

57 and provides a framework for adaptive resource management (e.g., Anderson et

58 al. 2008, Brekke et al. 2009). Global climate models (GCMs; Meehl et al. 2007)

59 do not uniformly sample model uncertainties, and are not independent (Pennell

60 and Reichler, 2011). Therefore the distributions shown here are not true estimates

61 of the probability of future climate changes, rather are best-guess estimates of

62 future climate change given current simulations. We compare our projections of $\mathrm{T}$

63 and $\mathrm{P}$ changes to natural internal climate variability, so that the relative magnitude

64 of the two can be assessed.

65 Spatial downscaling is necessary in California, which is topographically complex.

66 We use daily results from two GCMs dynamically downscaled with three different

67 regional climate models; the same two global models plus two more statistically

68 downscaled on a daily timescale; and the same 4 models plus 12 more (some with

69 multiple ensemble members) statistically downscaled by a different technique on a

70 monthly timescale. In total, we incorporate data from 45 runs originally generated

71 by 16 different global models. The secondary purpose of this work is to compare

72 the climate projections from the dynamical and statistical downscaling techniques

73 and address how they systematically differ. Natural internal climate variability is 
74 included to the extent that the original GCMs simulate it (cf. AchutaRao and

75 Sperber, 2006).

76 Climate change over California has been extensively studied using some

77 combination of single or multiple GCMs and statistical or dynamical downscaling

78 (e.g., Dickinson et al. 1989; Giorgi et al. 1994; Pan et al. 2001; Kim 2001 and

79 2005; Snyder et al. 2002; Hayhoe et al., 2004; Leung et al. 2004; Brekke et al.

80 2004; Maurer and Duffy 2005; Snyder and Sloan 2005; Duffy et al. 2006; Maurer

81 2007; Liang et al. 2008; Caldwell et al. 2009; Chin et al. 2010). Some common

82 themes emerge from these efforts. First, different GCMs produce different

83 warming and precipitation changes. Second, regional climate models (RCMs)

84 introduce another source of variation, even with the same driving GCM. Third,

85 temperature changes over California are consistently positive, but precipitation

86 changes vary in sign. Fourth, even with the divergent precipitation projections, the

87 effect on California's hydrology is substantial; snowpack declines and runoff

88 shifts to earlier in the water year, with elevation-dependent effects due to the

89 colder temperatures at higher elevations. And fifth, all model simulations exhibit

90 biases, which are assumed to systematically affect the projected climate as well.

91 Given this body of previous work, it is perhaps surprising that major gaps remain.

92 Few of the studies approached the problem probabilistically, and only Leung et al.

93 2004, Hayhoe et al. 2004, and Kim 2005 analyze the future daily data, which is

94 critical to energy use, agriculture, ecology, flooding, and water management.

95 Finally, none of the studies used both statistical and dynamical downscaling and

96 compared the two (cf. Hay and Clark 2003, who used both, but over the historical

97 period only and examined runoff rather than T and P). Similar issues have been

98 addressed in other regions; for example, Europe in the PRUDENCE (Christensen

99 et al., 2007) and ENSEMBLES (Kjellstrom and Giorgi, 2010) projects, and the

100 UK with the Climate Projections project

101 (http://ukclimateprojections.defra.gov.uk/).

102 Pierce et al. (2009) examined 40-year periods over the western U.S., and found

103 that 14 runs developed from 5 global models reliably conveyed the information

104 from the full set of 21 CMIP-3 model results. The bulk of results shown here are

105 generated using monthly data from all 45 runs (developed from 16 global models), 
106 so should be reliable even though the spatial and time scales considered here are

107 somewhat smaller than used in Pierce et al. (2009) (California vs. the western

108 U.S., 10-yr vs. 40-yr periods) and natural internal variability becomes more

109 evident at smaller scales (e.g., Hawkins and Sutton 2010). However the analysis

110 shown here was also done with a subset of 25 runs (excluding multiple ensemble

111 members for any single model) and the results were little different, which suggests

112 that our sampling of available climate model ensemble members is adequate.

113 Some of our results are from the 9 daily runs developed from 4 global models,

114 which falls short of the ideal number of runs and global models to use. However

115 Pierce et al. (2009) demonstrates that the large majority of the increase in multi-

116 model ensemble averaged skill occurs when going from 1 to 4 global models. We

117 therefore believe that the daily results shown here, obtained from the 9 runs

118 (incorporating information from 4 global models), are both a credible first analysis

119 of the problem and a roadmap showing how the multi-model probabilistic

120 treatment could be extended with additional runs in the future.

\section{2. Data and Methods}

122 We used dynamical downscaling with 3 regional climate models (RCMs): the

123 Regional Climate Model version 3 (RegCM3), which is derived from NCAR's

124 MM5 mesoscale model (Pal et al. 2007); the NCAR/NCEP/FSL Weather

125 Research and Forecasting (WRF) model (Skamarock et al., 2008); and the

126 Regional Spectral Model (RSM, Kanamitsu et al., 2005), which is a regional

127 version of the National Centers for Environmental Prediction (NCEP) global

128 spectral model. Details of the RCMs are given in the Supplemental Material,

129 section 1. Miller et al. (2009) examined the ability of the RCMs used here to

130 simulate California's historical climate when driven with boundary conditions

131 from the NCEP reanalysis II (Kanamitsu et al. 2002), and compared their

132 climatology to observations. That work concluded that all the models have

133 limitations, particularly in parameterized process such as cloud formation, but that

134 "they perform as well as other state-of-the-art downscaling systems, and all do a

135 credible job simulating the historical climate of California" (see also the

136 supplementary information). 
137 We used two methods of statistical downscaling: Bias Correction with

138 Constructed Analogues (BCCA; Hidalgo et al., 2008; Maurer et al. 2010), and

139 Bias Correction with Spatial Disaggregation (BCSD; Wood et al. 2002, 2004)

140 These methods were compared in Maurer and Hidalgo (2008), who concluded that

141 they have comparable skill when downscaling monthly fields of temperature and

142 precipitation. However only BCCA preserves the daily sequence of original global

143 model variability, which is of interest here. Details of the statistical techniques are

144 given in the Supplemental Material, section 2. Some of the BCSD ensemble

145 members were downloaded from the Bias Corrected and Downscaled WCRP

146 CMIP3 Climate Projections archive at http://gdo-

147 dcp.ucllnl.org/downscaled_cmip3_projections (Maurer et al., 2007).

148 All downscaling is to an approximately a $1 / 8^{\mathrm{O}} \times 1 / 8^{\mathrm{O}}(\sim 12 \mathrm{~km})$ spatial resolution.

149 Table 1 lists the various models and number of ensemble members used for each

150 downscaling technique. Not all GCMs were downscaled with all techniques,

151 because of the computer time required and lack of daily data for all the GCMs.

152 Only limited time periods were covered: 1985-94 (the "historical period") and

153 2060-2069 (the "future period"). Also, only the SRES A2 emissions scenario is

154 used. We note that the 2060s is about the last decade where globally averaged

155 surface temperatures from the A2, B1, and A1B emissions scenarios do not show

156 a clear separation (IPCC 2007). For the dynamical and BCCA downscaling,

157 CMIP-3 ensemble number 1 was used when more than one ensemble member was

158 available.

159 The 10-year spans are too short to examine natural climate variability from El

160 Nino/Southern Oscillation (ENSO) and the Pacific Decadal Oscillation (PDO) in

161 any one model run. However, we partially make up for this by using 4 to 16

162 models at a time (depending on the downscaling technique). Natural internal

163 climate variability due to ENSO and the PDO is not synchronized across model

164 runs due to the chaotic nature of the atmosphere. So, for example, one model run

165 might be simulating positive ENSO conditions in model year 2065 while another

166 model run might be simulating negative ENSO conditions. Although both ENSO

167 and the PDO affect California temperature and precipitation, averaging across

168 unsynchronized runs randomly samples different phases of these phenomena,

169 which reduces the net effect of they have on our estimates of anthropogenic 
170 climate change by the 2060's. We do not discard these estimates of natural

171 variability; rather we compare our estimates of anthropogenic climate change to

172 the magnitude of this natural variability so that a better understanding of the

173 relative magnitude of each can be obtained.

174 Results are presented as averages over the 11 California climate regions identified

175 by Abatzoglou et al. (2009). These regions do a better job representing

176 California's diverse mix of climate regimes than the standard U.S. climate

177 divisions.

\subsection{Bias correction}

All T and P fields, whether downscaled statistically or dynamically, underwent a bias correction procedure (Panofsky and Brier 1968; Maurer et al. 2002; Wood et al. 2002, 2004; Maurer 2007; Maurer et al. 2010). This is necessary because the project's focus was on hydrological and other applications, and even current stateof-the-art GCMs/RCMs generate T and P fields with biases, often due to biases in the original global fields (e.g., Wood et al. 2004, Duffy et al. 2006, Liang et al. 2008). Details of the bias correction procedure are given in the Supplemental Material, section 3.

\section{Results}

The probabilistic framework requires that several model runs be included to provide a distribution of projected outcomes. In this work we weight all combinations of global model and downscaling technique equally (except for the multiple ensemble members available from a single global model using BCSD, as described below), following the approach used in the last IPCC assessment (IPCC, 2007). Pierce et al. (2009) looked specifically at the western U.S. and concluded that weighting by model quality does not make a difference to climate projections until after the time period considered here (the 2060s).

BCSD was the only downscaling technique that had multiple downscaled ensemble members available from the same global model (Table 1). When analyzing mean quantities, we combined multiple BCSD downscaled results from 
199 the same global model into a single model mean before analysis, so that each

200 global model contributes equally to the BCSD result despite the disparate number

201 of ensemble members. When computing variability measures this averaging is not

202 appropriate, since averaging reduces the range of variability. In these cases we

203 used a Monte-Carlo approach, constructing 1000 random sets of BCSD results

204 where each model contributed one randomly picked ensemble member. Results

205 shown here are the average obtained across the 1000 random trials. In practice

206 however this makes little difference, as the BCSD results are well sampled even

207 excluding the extra ensemble members.

\section{$208 \quad 3.1$ Temperature changes}

209 Figure 1 (upper) shows the temperature changes by the 2060s, averaged across all

210 models and downscaling techniques. The yearly-averaged warming is on the order

211 of $2.4 \mathrm{C}$. The coastal regions experience less warming due to the ocean's

212 moderating influence, with a typical value of about $1.9 \mathrm{C}$. Inland locations show

213 warming approaching $2.6 \mathrm{C}$, which may have the potential to suppress coastal

214 warming further via enhanced sea breezes in some locations (Snyder et al. 2003;

215 Lebassi et al. 2009). The lower panels of Fig. 1 show climatological fields for

216 reference.

217 The mean warming has a pronounced seasonal signature, with the most warming

218 ( 3 C) in the summer (June-July-August), and the least warming $(<2 \mathrm{C})$ in the

219 winter (Dec-Jan-Feb). Since energy use in California is dominated by summer

220 cooling loads rather than winter heating loads, this warming pattern suggests that

221 peak energy use could increase faster than would be expected if only the yearly

222 averaged temperature changes were taken into account.

223 Figure 2 shows the change in individual monthly distributions of temperature,

224 displayed as a mapping between historic and future percentiles. For example, the

225 blue cross in panel a for the Sacramento/Central valley shows that the $50^{\text {th }}$

226 percentile temperature in the historical period ( $\mathrm{x}$ axis) will become the $17^{\text {th }}$

227 percentile value in the 2060s (y axis). The curves in Fig. 2a start at the origin,

228 which means that the coldest January monthly average temperatures in the

229 historical period will still be experienced in the 2060s. Relative to the evolving 
230 mean, the coldest months become much more dramatic in the future, which might

231 have implications for moving to crops better adapted to hotter conditions. Of the

23245 runs (Table 1), 16 have at least one January in the 2060s that is about as cold,

233 or colder, than the coldest historical January in the same model. Despite this, Fig.

234 2a shows that the median monthly January temperature in the future will be

235 warmer than 8 or 9 out of 10 Januarys today, and the warmest Januarys in the

236 future are completely off the historical distribution.

237 In July (Fig. 2b), the curves still start nearly at the origin, but inspection showed

238 that such a cold July only existed in two of the 45 runs. On the other hand, the

239 difference in the warmest months is profound. Over most of the state, the warmest

240 monthly average July found in the entire historical distribution of any model is

241 only a 15-40th percentile event in the future period. I.e., a July that is record-

242 breaking hot by current historical standards will become modestly cool in

243 comparison to the new mean.

244 The yearly warming simulated by the various downscaling techniques is shown in

245 Fig. 3. Results are illustrated for the GFDL 2.1 and CCSM3 global models. Global

246 model results are displayed in Fig. $3 \mathrm{f}$ and $3 \mathrm{k}$ for comparison. The downscaling

247 techniques generate similar values, and capture the decrease in warming near the

248 coast that is poorly resolved in the global field. BCCA produces a somewhat

249 weaker trend than the other methods for GFDL, although not for CCSM3 (cf.

250 Maurer and Hidalgo (2008), their Fig. 5).

$251 \quad 3.1 .1$ Distributions of seasonal temperature change

252 The exceedence probability of each year's seasonally averaged temperature

253 change in the future period is shown in Fig. 4. The data in this figure have been

254 re-sampled using the method described in Dettinger (2005), which fleshes out the

255 distributions using a principal component analysis-based resampling technique

256 applied to the variability around the model-mean climate change signal.

257 Figure 4 shows a distribution composed of one value per year (2060-69) from

258 each model, so each model run contributes 10 values. The values are presented

259 this way to include the effects of interannual natural internal climate variability. 
260 Over most of the domain, there is a 90\% chance of experiencing a warming of at

261 least $1 \mathrm{C}$ by the 2060 s, and a $10 \%$ chance the warming will reach $3-4 \mathrm{C}$

262 (depending on the season). Although summer (JJA) warming is largest in most of

263 the domain, across the southern regions the differences between the seasons

264 lessens, and autumn (Sep-Oct-Nov, SON) warming matches the JJA warming.

\subsubsection{Forced versus natural changes in temperature}

266 The distributions in Fig. 4 have contributions from three sources: 1) the average

267 warming across models; 2) the difference in warming between models; and 3)

268 natural internal climate variability. We estimate each simulation's mean warming

269 as the mean of the 10 yearly values in the future period minus the mean of the 10

270 values in the historical period. Each simulation's natural internal climate

271 variability is estimated from the difference between the 10 individual yearly

272 values in the future period and the mean of the 10 values in the future period. This

273 method underestimates the true natural internal variability since the 10-yr average

274 in the 2060s will itself be influenced by low-frequency natural variability. The

275 error introduced by this procedure can be estimated from the historical record, as

276 outlined in the supplemental material (Section 4). Errors are modest, on the order

277 of 6-14\% (Table SM2, column b). The displayed confidence intervals in Figs. 5

278 and 9 (blue bars) have been widened by these corrections.

279 Figure 5 shows the average warming, model spread, and estimate of natural

280 internal climate variability across the 11 climate regions. The annual mean model-

281 estimated warming by the 2060s (Fig. 5a green bars, degrees C) is larger than the

$28290 \%$ confidence interval of natural internal variability (blue bars) in all regions. In

283 practice, this means that the warming will be easily noticeable in the yearly

284 average. The red lines show the $90 \%$ confidence interval in estimated warming

285 across the models. The model-to-model variability is small compared to the

286 magnitude of the projected warming. Even if we knew that one of the models used

287 here was perfect and the rest wrong, it would make little difference to the

288 warming estimates.

289 The seasonal results in Fig. 5 tend to show a larger contribution from natural

290 variability, which is understandable since fewer days are being averaged over. 
291 This is most pronounced in winter (DJF, Fig. 5b), where the typical scale of year-

292 to-year natural fluctuations in seasonally-averaged temperature is roughly twice

293 the expected shift in temperatures. The uncertainly across models (red line) is a

294 larger fraction of the mean warming as well. These tendencies are minimized in

295 summer (JJA, Fig. 5d), where the temperature shifts are as large compared to the

296 natural internal climate variability as seen in the yearly average.

\subsubsection{Changes in daily temperature}

298 Only data pooled across the BCCA and dynamical downscaling techniques (which

299 are based on the GCM's daily data) have been used for daily analyses of

300 temperature and precipitation.

301 Figure 6a shows the cumulative distribution function of daily maximum

302 temperature in July for the historical period (blue) and future period (red). An

303 error function transformation is used on the $\mathrm{Y}$ axis, so a Gaussian distribution

304 would form a straight line. All regions show a shift to a higher likelihood of

305 warmer daily maximum temperatures at all probability levels. The shift is smallest

306 at the warmest temperatures in the Northern and central coastal regions, perhaps

307 because of the moderating influence of cool ocean temperatures typically seen in

308 summer along California's coast. Similar curves for daily July minimum

309 temperature display more Gaussian behavior (straighter lines) and lack the

310 reduced warming along the coast (not shown).

311 By contrast, January daily minimum temperatures (Fig. 6b) show more warming

312 at the highest percentile values and little change below the median. The

313 experience on the ground in January will not be an increase in every day's

314 minimum temperature so much as the appearance of rare days with temperature

315 several degrees warmer than experienced before. While the slopes of the lines in

316 Fig. 6a (July) tend to be the same or slightly steeper in the future, indicating

317 similar or slightly reduced daily variability, the slopes of the lines in Fig. $6 \mathrm{~b}$ (Jan)

318 tend to be flatter in the future, indicating greater daily variability in projected

319 January daily minimum (and maximum, not shown) temperatures. 
320 Three-day averages of maximum daily temperature in summer (Fig. 7) are of

321 interest to the energy industry, because people are more likely to use air

322 conditioning by the third hot day. The shifts seen here are proportionally much

323 greater than in Fig. 6. Also, in all the inland locations the divergence between the

324 historical and future distribution becomes more pronounced at the warmest

325 temperatures. In the San Joaquin valley, a 3-day run of $40 \mathrm{C}$ or warmer

326 temperatures is only a 1 -in-100-yr occurrence in the historical simulations, but is a

327 1-in-2-yr occurrence in the future simulations. The simulated 3-day average

328 warmest temperature in the Anza-Borrego region is $46 \mathrm{C}$ in the historical era, but

$32951 \mathrm{C}$ in the future era. Increases along the coast are $\sim 2 \mathrm{C}$, although even there the

330 incidence of 3-day maximum temperatures with a probability of $<0.01$ in the

331 historical era increases by a factor of 10 .

\section{$332 \quad 3.2$ Precipitation changes}

333 The upper panels of Fig. 8 shows the mean precipitation change (\%) by the 2060s,

334 averaged across all models and downscaling techniques (45 runs total). Lower

335 panels show climatological fields for comparison. In the annual average (8a), the

336 overall tendency is for small decreases in precipitation in the southern part of the

337 state $(<10 \%)$, and negligible changes in the North. The patterns by season are

338 more pronounced, with the northern part of the state experiencing wetter

339 conditions in winter that are nearly offset by drier conditions in the rest of the

340 year. The southern part of the state shows moderate fractional decreases in

341 precipitation in fall, winter and spring but a strong increase in summer

342 precipitation, which will be discussed more below. Bear in mind that California is

343 climatologically dry in the summer, so the large percentage increases found at that

344 time represent small amounts.

\section{$345 \quad$ 3.2.1 Forced versus natural changes in precipitation}

346 Projected changes in seasonal-mean precipitation tend to be small compared to

347 natural internal climate variability (Fig. 9). The blue bars (90\% confidence

348 interval of natural variability, tenths of $\mathrm{mm} /$ day) are generally an order of

349 magnitude larger than the mean model changes (green bars). At the same time, the

350 spread across the models (red lines) is typically larger than the mean model 
change, except for the JJA decrease in precipitation across the northern part of the state (Fig. 9d). However, even precipitation shifts that are small compared to the inter-seasonal or inter-annual variability can be important for the long term water

354 balance of a region, especially where the water supply has little room for reduction. California droughts can last 5-10 years, a long enough averaging period

356 to reduce natural variability sufficiently to expose small but systematic

357 precipitation shifts.

\subsubsection{The influence of downscaling technique}

359 The effect of downscaling technique on precipitation must be interpreted

360 cautiously, since not all models were downscaled with all techniques. As a group,

361 the global models downscaled with a daily technique (either dynamical or BCCA)

362 happened to be drier than the average global model by about 10 percentage points

363 in the annual average. In general, the BCCA and dynamical downscaling tend to

364 make the simulation wetter than the original global model field in all regions,

365 typically by about 9-14 percentage points. In the monsoon-influenced region in

366 the southeast of the state this tendency is so strong, the downscaling reverses the

367 sign of the global model projections.

368 The difference between downscaling techniques can be isolated by using a single

369 global model at a time. Figure 10 shows the yearly precipitation change (\%)

370 simulated by the different downscaling techniques applied to the GFDL 2.1 and

371 CCSM3 global model runs, along with the global fields for comparison. The

372 downscaling methods all gave similar results for temperature (Fig. 3). However,

373 for precipitation the agreement depends on the global model. The top row of Fig.

37410 shows the different downscaling techniques give similar results when applied

375 to the GFDL 2.1 global model. However the bottom row of Fig. 10 shows that

376 different downscaling methods give quite different results for CCSM3 (i.e., Fig.

$37710 \mathrm{~g}$ vs. Fig. $10 \mathrm{j}$ ), with the statistical methods most similar to the global GCM

378 signal.

379 The diversity of responses in CCSM3 can be understood, in large part, by

380 considering the details of precipitation changes in each season. Figures 11a and

381 11b show the statistical downscaling methods applied to CCSM3, while Figs. 11c 
and $11 \mathrm{~d}$ show the dynamical methods. Each panel shows the regions in roughly

383 geographical order, and each region has a set of 4 bars showing the climatological

384 seasonal precipitation in mm (DJF, MAM, JJA, and SON, counting the bars from

385 left to right) and the change in precipitation in $\mathrm{mm}$ projected by the downscaling

386 technique (colored portion of the bars). Both dynamical methods show 20-30\%

387 precipitation increases in winter, while the statistical methods show increases of

388 less than $10 \%$. Both statistical methods show MAM and SON decreases in

389 precipitation of $20-30 \%$, while the dynamical methods show precipitation

390 decreases of $<10 \%$. In other words, the statistical and dynamical downscaling

391 technique are showing the same patterns, but with different weighting by season.

392 Depending on how the oppositely-signed tendencies are weighted, the yearly

393 average difference can be positive or negative.

394 What determines the differences between a global model trend and the

395 corresponding dynamically downscaled trend? This is addressed in Fig. 12, which

396 shows a selection (DJF and JJA) of seasonally downscaled fields driven by the

397 GFDL and CCSM3 global models. The values plotted are the differences

398 (percentage points) between the dynamically downscaled precipitation changes

399 and the changes found in the original global model. In other words, they are

400 differences of differences, and show not the future precipitation changes, but

401 rather how dynamical downscaling alters the original global model trends. In DJF,

402 the consistencies between the downscaled fields using GFDL (12a, 12e, 12i), and

403 the consistencies between the downscaled fields using CCSM3 (12c, 12g) are

404 greater than the consistencies using the same downscaling technique but a

405 different global model (12a vs. 12c, and 12e vs. 12g). This suggests that in DJF,

406 the effect of dynamical downscaling is influenced primarily by the global model

407 characteristics (e.g., the large-scale atmospheric circulation), and is less sensitive

408 to the dynamical downscaling model used.

409 In summer, in the southern half of the state, RSM (12f, 12h) tends to show much

410 wetter changes than the global models (either GFDL or CCSM3), while WRF

411 (12b, 12d) shows much drier changes than the global models (either GFDL or

412 CCSM3). The changes produced by RegCM3 lie in between (12j). This indicates

413 that summer precipitation is influenced more by the particular parameterizations

414 used by an individual dynamical downscaling model than by the global driving 
415 model. In the case of RSM, this is despite the fact that spectral nudging is used to

416 keep the regional model results from diverging too greatly from the original global

417 model fields.

\section{3.2.3 Changes in daily precipitation}

419 Three-day accumulations of precipitation can be used to understand the potential

420 for flooding (e.g. Das et al. 2011), as it typically takes a few days for the soil to

421 saturate during a storm. The distributions of the maximum three-day accumulation

422 in a calendar year are shown in Fig. 13. Nearly all of California shows striking

423 increases in maximum three-day accumulations, in many instances generating

424 values far outside the historical distribution. Similar results were found in Kim

425 (2005), although that work considered snow/rain distinctions that we are not

426 examining here. Along the Northern coast, the historical distribution tops out at 80

$427 \mathrm{~mm} /$ day with a $0.01 /$ year chance. In the future, that same value has a greater than

$4280.1 /$ year chance, and the distribution now extends up to $120 \mathrm{~mm} / \mathrm{day}$.

429 For planning purposes it can be useful to know whether the distributions of

430 temperature and precipitation change are related. For example, perhaps the

431 warmest projections are also the driest. However, we find no evidence that the

432 changes in temperature and precipitation distributions are linked in any season.

\section{4. Summary and Conclusions}

434 Our purpose has been to present probabilistic projections of temperature (T) and

435 precipitation $(\mathrm{P})$ changes in California by the 2060s. We have included daily

436 distributions, since a number of important applications in energy demand, water

437 management, and agriculture require daily information. We focused on

438 probabilistic estimates and included natural internal climate variability, because it

439 is useful for planners to understand the range of climate projections and how those

440 compare to natural climate fluctuations.

441 We downscaled data from 16 global models using a combination of two statistical

442 techniques (BCSD and BCCA) and three nested regional climate models (WRF,

443 RCM, and RegCM3), although not all GCMs were downscaled with all 
444 techniques. In total, we analyzed 9 runs with daily data, plus another 36 with

445 monthly data. As expected, the statistically downscaled fields tend to be closer to

446 the original global model simulations than do the dynamically downscaled fields.

447 All downscaling techniques were combined with equal weighting; exploring the

448 implications of weighting schemes for different downscaling techniques would be

449 a useful future extension of this work. We analyzed a historical (1985-1994) and

450 future (2060-2069) time period, using one emissions scenario, SRES A2. Our

451 estimates of natural internal variability are computed from the available 10-year

452 time slices and adjusted upwards (based on an analysis of observations) to correct

453 for the limited time period included. As appropriate given our focus on

454 applications, all model output was bias corrected.

455 We find that January-averaged temperatures as cold as any found in the historical 456 period are still seen in the 2060s, although rarer. Januarys warmer than any found 457 in the historical period are seen about $20 \%$ of the time. By contrast, cold Julys

458 (judging by current historical standards) nearly disappear by the 2060s, and the

459 hottest July average temperature found in any simulation's historical period

460 becomes a moderately cool event $\left(15-40^{\text {th }}\right.$ percentile) by the 2060 s. The warmest

461 Julys are likely to be far outside the historical experience; proportionally, the gain

462 in warm months will be much larger than the loss of cold months.

463 The downscaled $\mathrm{T}$ projections tend to agree across downscaling techniques. Year-

464 to-year variability in seasonally averaged $\mathrm{T}$ is about twice as large as the mean

465 seasonal climate warming in winter, and about half the mean warming in summer.

466 In either season, the model range in projected warming is about half the mean

467 warming signal.

468 Distributions of July daily maximum $\mathrm{T}$ shift more or less uniformly towards 469 warmer values, except along the Northern coast, where maximum values are less 470 changed from today. In January, the distributions are little changed below the 471 median, but show a shift towards a greater incidence of a few particularly warm

472 winter days. Distributions of the warmest 3-day average T, which drive air

473 conditioner demand, show approximately uniform shifts of $+2 \mathrm{C}$ across the 474 distribution. 
475 Averaged across all models and downscaling techniques, weak annual mean

476 decreases in precipitation are found in the southern part of the state, and near zero

$477 \quad \mathrm{P}$ change in the northern part of the state. The disagreement across models is

478 large, however. Winters tend to become wetter in the north, spring and autumn

479 show strong decreases in precipitation, and summer (when the actual values of $\mathrm{P}$

480 are quite small) shows less precipitation in the north but more in the south.

481 Natural variability is typically more than an order of magnitude greater than these

482 seasonally-averaged changes, and the range of projections across models includes

483 zero, except in summer and the southern part of the state in spring.

484 The different downscaling techniques agree less for annual $\mathrm{P}$ changes than they do

485 for $\mathrm{T}$ changes. This is due to the annual $\mathrm{P}$ change in most models being made up

486 of competing effects, with a tendency towards more winter precipitation and less

487 spring/autumn precipitation. Different models and downscaling techniques weight

488 these competing seasonal effects differently, which can result in a positive or

489 negative change in the yearly average.

490 The dynamical downscaling techniques show larger increases in summer $\mathrm{P}$ in the

491 region affected by the North American monsoon than found with the statistical

492 downscaling techniques. Regional dynamical models are able to amplify monsoon

493 effects that are only coarsely represented by the GCM's, but statistical

494 downscaling has no way to sharpen these features. In general, the winter P

495 response seems more sensitive to which GCM was used, while the summer P

496 response seems more sensitive to which RCM was used. A similar finding was

497 reported in Pan et al. (2001).

498 There is a substantial increase in 3-day maximum precipitation, with peak values

499 increasing 10-50\%, in agreement with Kim (2005). The increases are largest in the

500 northern part of the state, where values that have only a 0.01 probability of

501 occurrence in the historical period become 10 times more likely by the 2060s.

502 Our results have wide application to the needs of resource managers and other

503 decision makers when adapting to forthcoming climate change in California. In

504 the realm of water management, the pronounced increase in maximum 3-day

505 precipitation accumulation has implications for flooding. Likewise, these results 
506 shed more light on the global model finding that California will generally

507 experience small changes in annual mean precipitation. We show that these small

508 annual mean changes are hiding much larger seasonal changes, with wetter

509 conditions in winter and sharply drier conditions in spring and autumn, although

510 even these seasonal changes are small compared to the natural variability.

511 Generally the simulations suggest that the extreme southeast of the state will

512 experience more summer rainfall as the North American monsoon intensifies,

513 although not all the different downscaling techniques agree as to the magnitude

514 and sign of this response. Probabilistic multi-model climate change evaluations

515 such as those developed here will enable a better understanding of how to adapt to

516 climate change's effects over California.

\section{Acknowledgements}

518 This work was funded by the public interest energy research (PIER) program of the California

519 Energy Commission (CEC), grant 500-07-042 to the Scripps Institution of Oceanography at UC

520 San Diego: Development of probabilistic climate projections for California. We would also like to

521 thank the global modeling groups that contributed data to the CMIP-3 archive; without their efforts

522 and generosity in sharing the data, this work would have been impossible. DWP also received

523 partial support from the International ad-hoc Detection and Attribution (IDAG) project from the

524 US Department of Energy's Office of Science, Office of Biological and Environmental Research,

525 grant DE-SC0004956 and the National Oceanic and Atmospheric Administration's Climate

526 Program Office, and the Department of Energy grant DE-SC0002000 in furtherance of work to

527 examine how daily timescale weather events and the seasonality of precipitation change to

528 accomplish low frequency, global climate changes. Partial salary support for TD from the

529 CALFED Bay-Delta Program funded-postdoctoral fellowship grant is also acknowledged. 


\section{References}

531 Abatzoglou JT, Redmond KT, Edwards LM (2009) Classification of Regional Climate Variability

532 in the State of California. J App Meteor Clim 48:1527-1541

533 AchutaRao K, Sperber KR (2006) ENSO simulation in coupled ocean-atmosphere models: are the

534 current models better? Clim Dyn 27:1-15

535 Anderson J, Chung F, Anderson M, Brekke L, Easton D, Ejeta M, Peterson R, Snyder R (2008)

536 Progress on incorporating climate change into management of California's water resources.

537 Climatic Change 87 (Suppl 1):S91-S108, DOI 110.1007/s10584-10007-19353-10581.

538 Barnett TP, Pierce DW, Hidalgo HG, Bonfils C et al. (2008) Human-induced changes in the

539 hydrology of the western United States. Science 319:1080-1083

540 Bonfils C, Santer BD, Pierce DW, Hidalgo HG, Bala G, Das T, Barnett TP, Cayan DR, Doutriaux

541 C, Wood AW, Mirin A, Nozawa T (2008) Detection and Attribution of Temperature Changes in

542 the Mountainous Western United States. J Clim 21:6404-6424

543 Brekke LD, Miller NL, Bashford KE, Quinn NWT, Dracup JA (2004) Climate change impacts

544 uncertainty for water resources in the San Joaquin River Basin, California. J Amer Water Res

545 Assoc 40:149-164

546 Brekke LD, Maurer EP, Anderson JD, Dettinger MD, Townsley ES, Harrison A, Pruitt T (2009)

547 Assessing reservoir operations risk under climate change, Water Resour. Res., 45, W04411,

548 doi:10.1029/2008WR006941

549 Caldwell P, Chin HNS, Bader DC, Bala G (2009) Evaluation of a WRF dynamical downscaling

550 simulation over California. Clim Change 95:499-521

551 Cayan D, Leurs AL, Hanemann M, Granco G, Croes B (2006) Scenarios of climate change in

552 California: An overview. California Climate Change Center report CEC-500-2005-186-SF. 53 pp.

553 Chen W, Jiang Z (2011) Probabilistic Projections of Climate Change over China under the SRES

554 A1B Scenario Using 28 AOGCMs. J Clim 24:4741-56.

555 Chin HNS, Caldwell PM, Bader DC (2010) Preliminary Study of California Wintertime Model

556 Wet Bias. Mon Wea Rev 138:3556-3571

557 Christensen JH, Carter TR, Rummukainen M, Amanatidis G (2007) Evaluating the performance

558 and utility of regional climate models: the PRUDENCE project. Clim Change 81:1-6 
560 (2009) Structure and origins of trends in hydrological measures over the western United States. J

561 Hydromet, 10:871-892. doi:10.1175/2009JHM1095.1

562 Das T, Dettinger MD, Cayan DR, Hidalgo HG (2011) Potential increase in floods in Californian

563 Sierra Nevada under future climate projections. Clim Change 109 (Suppl 1):S71-94

564 Dettinger MD (2005) From climate-change spaghetti to climate-change distributions for 21st

565 century California. San Francisco Estuary and watershed science. 3:issue 1, article 4. 14 pp

566 Dickinson RE, Errico RM, Giorgi F, Bates GT (1989) A regional climate model for the western

567 United States. Clim Change 15:383-422

568 Duffy PB, Arritt RW, Coquard J, Gutowski W, Han J, Iorio J, Kim J, Leung LR, Roads J, Zeledon

569 E (2006) Simulations of present and future climates in the western United States with four nested

570 regional climate models. J Clim 19:873-895

571 Giorgi F, Brodeur CS, Bates GT (1994) Regional climate-change scenarios over the United States

572 produced with a nested regional climate model. J Clim 7:375-399

573 Hawkins E, Suntton R (2009) The potential to narrow uncertainty in regional climate predicints.

574 Bull Am Met Soc 90:1095-1106.

575 Hay LE, Clark MP (2003) Use of statistically and dynamically downscaled atmospheric model

576 output for hydrologic simulations in three mountainous basins in the western United States. J

577 Hydrol 282:56-75.

578 Hayhoe K, Cayan D, Field CB, Frumhoff PC and others (2004) Emissions pathways, climate

579 change, and impacts on California. Proc Nat Acad Sci 101:12422-12427

580 Hidalgo HG, Dettinger MD, Cayan DR (2008) Downscaling with Constructed Analogues: Daily

581 precipitation and temperature fields over the Unites States. California Energy Commission

582 technical report CEC-500-2007-123. 48 pp.

583 Hidalgo HG, Das T, Dettinger MD, Cayan DR, Pierce DW and others (2009) Detection and

584 Attribution of Streamflow Timing Changes to Climate Change in the Western United States. J

585 Clim 22:3838-3855

586 IPCC (2007) Climate change 2007: The physical science basis. Working group I contribution to

587 the fourth assessment report of the Intergovernmental Panel on Climate Change. Cambridge

588 University Press, Cambridge, United Kingdom and New York, USA. 996 pp.

589 Kanamitsu M, Ebisuzaki W, Woollen J, Yang SK et al. (2002) NCEP-DOE AMIP-II reanalysis

590 (R-2). Bull Am Met Soc 83:1631-1643 
591 Kanamitsu M, Kanamaru H, Cui Y, Juang H (2005) Parallel implementation of the regional

592 spectral atmospheric model. California Energy Commission technical report CEC-500-2005-014.

593 www.energy.ca.gov/2005publications/CEC-500-2005-014/CEC-500-2005-014.

594 Kim J (2001) A nested modeling study of elevation-dependent climate change signals in California

595 induced by increased atmospheric CO2. Geophys Res Lett 28:2951-2954

596 Kim J (2005) A projection of the effects of the climate change induced by increased $\mathrm{CO} 2$ on

597 extreme hydrologic events in the western US. Clim Change 68:153-168

598 Lebassi, B, González J, Fabris D, Maurer E, Miller N, Milesi C, Switzer P, Bornstein R (2009)

599 Observed 1970-2005 Cooling of Summer Daytime Temperatures in Coastal California. J. Clim

$600 \quad 22: 3558-3573$.

601 Leung LR, Qian Y, Bian XD, Washington WM, Han JG, Roads JO (2004) Mid-century ensemble

602 regional climate change scenarios for the western United States. Clim Change 62:75-113

603 Liang XZ, Kunkel KE, Meehl GA, Jones RG, Wang JXL (2008) Regional climate models

604 downscaling analysis of general circulation models present climate biases propagation into future

605 change projections. Geophys Res Lett 35 doi:10.1029/2007GL032849

606 Manning LJ, Hall JW, Fowler HJ, Kilsby CG, Tebaldi C (2009), Using probabilistic climate

607 change information from a multimodel ensemble for water resources assessment, Water Resour.

608 Res., 45, W11411, doi:10.1029/2007WR006674

609 Maurer EP, Wood AW, Adam JC (2002) A long-term hydrologically based dataset of land surface

610 fluxes and states for the conterminous United States. J Clim 15:3237-51

611 Maurer EP, Duffy PB (2005) Uncertainty in projections of streamflow changes due to climate

612 change in California. Geophys Res Lett 32, doi:10.1029/2004GL021462

613 Maurer EP (2007) Uncertainty in hydrologic impacts of climate change in the Sierra Nevada,

614 California, under two emissions scenarios. Clim Change 82:309-325

615 Maurer EP, Brekke L, Pruitt T, Duffy PB (2007) Fine-resolution climate change projections

616 enhance regional climate change impact studies, Eos, Transactions, American Geophysical Union,

617 88:504, doi:10.1029/2007EO470006

618 Maurer EP, Stewart IT, Bonfils C, Duffy PB, Cayan DR (2007) Detection, attribution, and

619 sensitivity of trends toward earlier streamflow in the Sierra Nevada, J. Geophy Res 112, D11118,

620 doi:10.1029/2006JD008088

621 Maurer EP, Hidalgo HG (2008) Utility of daily vs. monthly large-scale climate data: an

622 intercomparison of two statistical downscaling methods. Hydrol. Earth Syst. Sci., 12:551-563. 
623 Maurer EP, Hidalgo HG (2010) The utility of daily large-scale climate data in the assessment of

624 climate change impacts on daily streamflow in California. Hydrol. Earth Syst. Sci., 14:1125-1138,

625 doi:10.5194/hess-14-1125-2010

626 Meehl GA, Covey C, Delworth T, Latif M and others (2007) The WCRP CMIP3 multimodel

627 dataset - A new era in climate change research. Bull Am Met Soc 88:1383

628 Miller NL, Jin J, Schlegel NJ, Snyder MA et al. (2009) An analysis of simulated California climate

629 using multiple dynamical and statistical techniques. California Energy Commission report CEC-

630 500-2009-017-F, August, 2009. 47 pp.

631 Pal JS, Giorgi F, Bi XQ, Elguindi N et al. (2007) Regional climate modeling for the developing

632 world - The ICTP RegCM3 and RegCNET. Bull Amer Met Soc 88:1395

633 Pan Z, Christensen JH, Arritt RW, Gutowski WJ, Takle ES, Otieno F (2001) Evaluation of

634 uncertainties in regional climate change simulations. J Geophys Res Atmos 106:17735-17751

635 Panofsky HA. Brier GW (1968) Some Applications of Statistics to Meteorology, The Pennsylvania State

636 University, University Park, PA, USA, 224 pp.

637 Pennell C, Reichler T (2011) On the Effective Number of Climate Models. J. Clim, 24:2358-2367.

638 doi: 10.1175/2010JCLI3814.1

639 Pierce DW, Barnett TP, Hidalgo HG, Das T et al. (2008) Attribution of Declining Western US

640 Snowpack to Human Effects. J Clim 21:6425-6444

641 Pierce DW, Barnett TP, Santer BD, Gleckler PJ (2009) Selecting global climate models for

642 regional climate change studies. Proc Nat Acad Sci 106:8441-8446

643 Skamarock WC, Klemp JB, Duidhia J, Gill DO, Barker DM, Duda MG, Huang X-Y, Wang W,

644 Powers JG (2008): A description of the Advanced Research WRF Version 3. NCAR technical note

645 NCAR/TN-475+STR. 125 pp.

646 Snyder MA, Bell JL, Sloan LC, Duffy PB, Govindasamy B (2002) Climate responses to a

647 doubling of atmospheric carbon dioxide for a climatically vulnerable region. Geophys Res Lett

$648 \quad 29: 4$

649 Snyder MA, Sloan LC, Diffenbaugh NS, Bell JL (2003) Future climate change and upwelling in

650 the California Current. Geophys. Res Lett 30:1823

651 Snyder MA, Sloan LC (2005) Transient future climate over the western United States using a

652 regional climate model. Earth Interactions v. 9 paper 11.

653 Wood AW, Maurer EP, Kumar A, Lettenmaier DP (2002) Long-range experimental hydrologic 654 forecasting for the eastern United States. J Geophys Res Atmos 107 , doi:10.1029/2001jd000659 
655 Wood AW, Leung LR, Sridhar V, Lettenmaier DP (2004) Hydrologic implications of dynamical 656 and statistical approaches to downscaling climate model outputs. Clim Change 62:189-216 


\begin{tabular}{|c|c|c|c|c|c|c|}
\hline GCM & Institution & BCSD & BCCA & WRF & RSM & RegCM3 \\
\hline $\begin{array}{l}\text { BCCR BCM } \\
2.0\end{array}$ & $\begin{array}{l}\text { Bjerknes Centre Clim. Res., } \\
\text { Bergen, Norway }\end{array}$ & 1 & & & & \\
\hline $\begin{array}{l}\text { CCCMA } \\
\text { CGCM3.1 }\end{array}$ & $\begin{array}{l}\text { Canadian Centre, } \\
\text { Victoria, B.C., Canada }\end{array}$ & 5 & & & & \\
\hline $\begin{array}{l}\text { CNRM } \\
\text { CM3 }\end{array}$ & $\begin{array}{l}\text { Meteo-France, Toulouse, } \\
\text { France }\end{array}$ & 1 & 1 & & & \\
\hline $\begin{array}{l}\text { CSIRO } \\
\text { MK3.0 }\end{array}$ & $\begin{array}{l}\text { CSIRO Atmos. Res., } \\
\text { Melbourne, Australia }\end{array}$ & 1 & & & & \\
\hline $\begin{array}{l}\text { GFDL } \\
\text { CM2.0 }\end{array}$ & $\begin{array}{l}\text { Geophys. Fluid Dyn. Lab, } \\
\text { Princeton, NJ, USA }\end{array}$ & 1 & & & & \\
\hline $\begin{array}{l}\text { GFDL } \\
\text { CM2.1 }\end{array}$ & $\begin{array}{l}\text { Geophys. Fluid Dyn. Lab, } \\
\text { Princeton, NJ, USA }\end{array}$ & 1 & 1 & 1 & 1 & 1 \\
\hline GISS e_r & $\begin{array}{l}\text { NASA/Goddard Inst. Space } \\
\text { Studies, N.Y., USA }\end{array}$ & 1 & & & & \\
\hline INMCM 3.0 & $\begin{array}{l}\text { Inst. Num. Mathematics, } \\
\text { Moscow, Russia }\end{array}$ & 1 & & & & \\
\hline IPSL CM4 & $\begin{array}{l}\text { Inst. Pierre Simon Laplace, } \\
\text { Paris, France }\end{array}$ & 1 & & & & \\
\hline $\begin{array}{l}\text { MIROC } 3.2 \\
\text { medres }\end{array}$ & $\begin{array}{l}\text { Center Climate Sys. Res., } \\
\text { Tokyo, Japan }\end{array}$ & 3 & & & & \\
\hline $\begin{array}{l}\text { MIUB } \\
\text { ECHO-G }\end{array}$ & $\begin{array}{l}\text { Meteor. Inst. U. Bonn, Bonn, } \\
\text { Germany }\end{array}$ & 3 & & & & \\
\hline $\begin{array}{l}\text { MPI- } \\
\text { ECHAM5 }\end{array}$ & $\begin{array}{l}\text { Max Planck Inst. Meteor., } \\
\text { Hamburg, Germany }\end{array}$ & 3 & & & & \\
\hline $\begin{array}{l}\text { MRI } \\
\text { CGCM2.3.2 }\end{array}$ & $\begin{array}{l}\text { Meteor. Res. Inst., Tsukuba, } \\
\text { Ibaraki, Japan }\end{array}$ & 5 & & & & \\
\hline $\begin{array}{l}\text { NCAR } \\
\text { CCSM3 }\end{array}$ & $\begin{array}{l}\text { Nat. Center Atmos. Res., } \\
\text { Boulder, CO, USA }\end{array}$ & 4 & 1 & 1 & 1 & \\
\hline $\begin{array}{l}\text { NCAR } \\
\text { PCM1 }\end{array}$ & $\begin{array}{l}\text { Nat. Center Atmos. Res., } \\
\text { Boulder, CO, USA }\end{array}$ & 4 & 1 & & & \\
\hline $\begin{array}{l}\text { UKMO } \\
\text { HadCM3 }\end{array}$ & $\begin{array}{l}\text { UK Met Office, Exeter, } \\
\text { Devon, UK }\end{array}$ & 1 & & & & \\
\hline
\end{tabular}

659 Table 1. The global general circulation models (GCMs) used in this project, their

660 originating institution, and the number of ensemble members downscaled by the

661 indicated method. BCSD: bias correction with spatial disaggregation; BCCA: bias

662 correction with constructed analogues; WRF: weather research forecast model;

663 RSM: regional spectral model; RegCM3: Regional climate model version 3. 

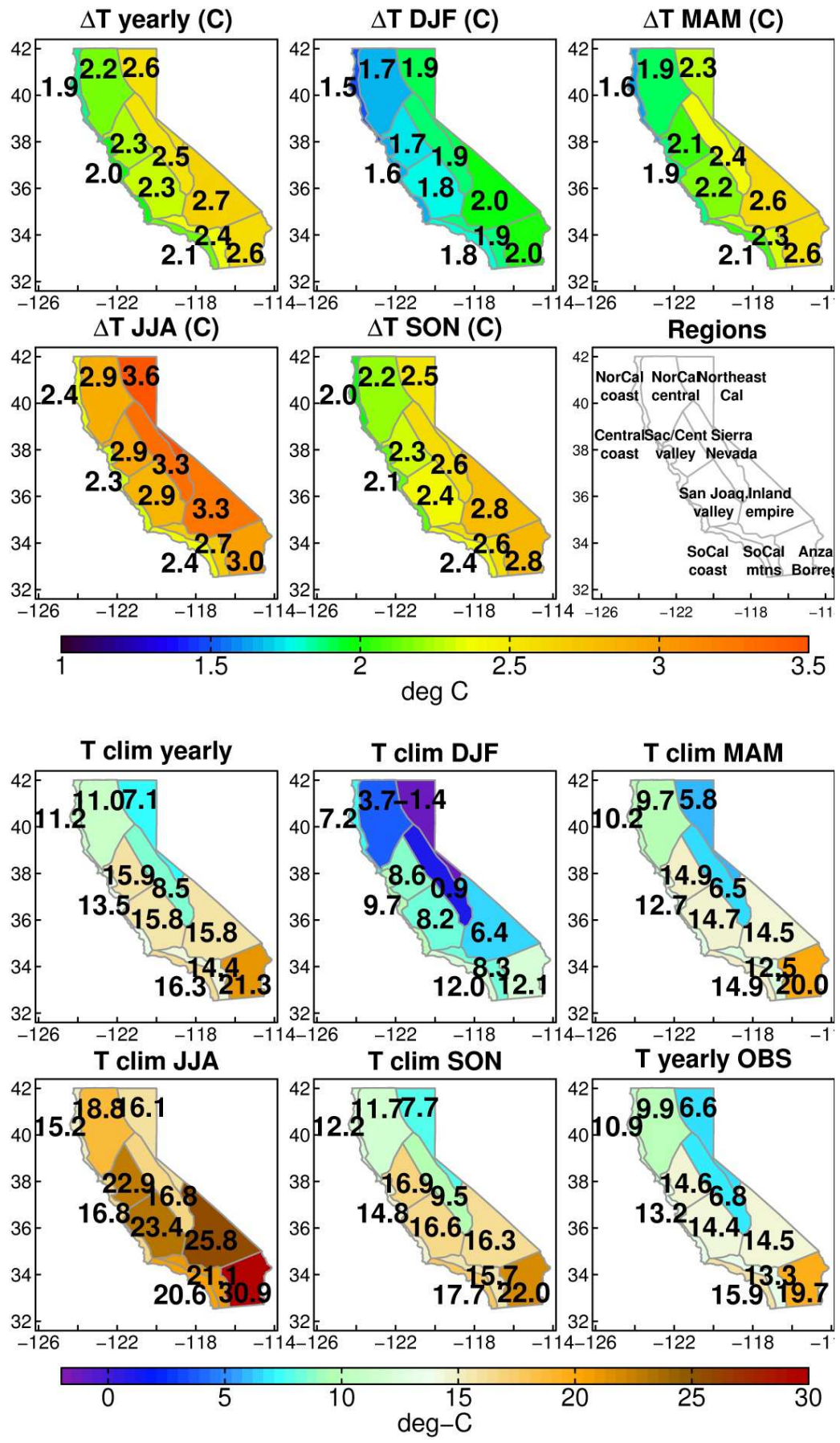

665 Figure 1. Upper: temperature change $\left({ }^{\circ} \mathrm{C}\right)$ from years 1985-94 to 2060-69. The seasonally-

666 averaged data from all models and downscaling techniques was averaged across models to

667 generate the values. The regions used in this work are also shown. Lower: temperature climatology

$668\left({ }^{\circ} \mathrm{C}\right)$ averaged across the models, and observed annual mean for comparison (lower right). 
a) January
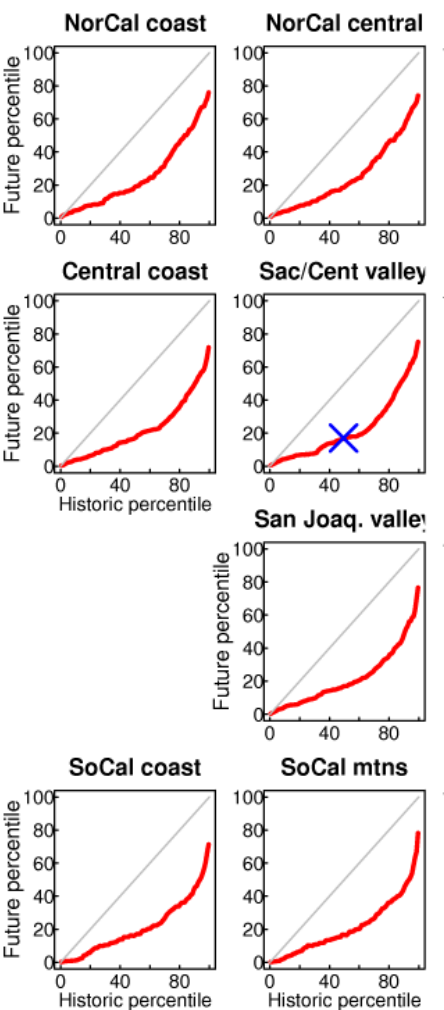
from all 45 model runs.

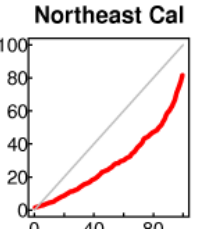

\section{b) July}
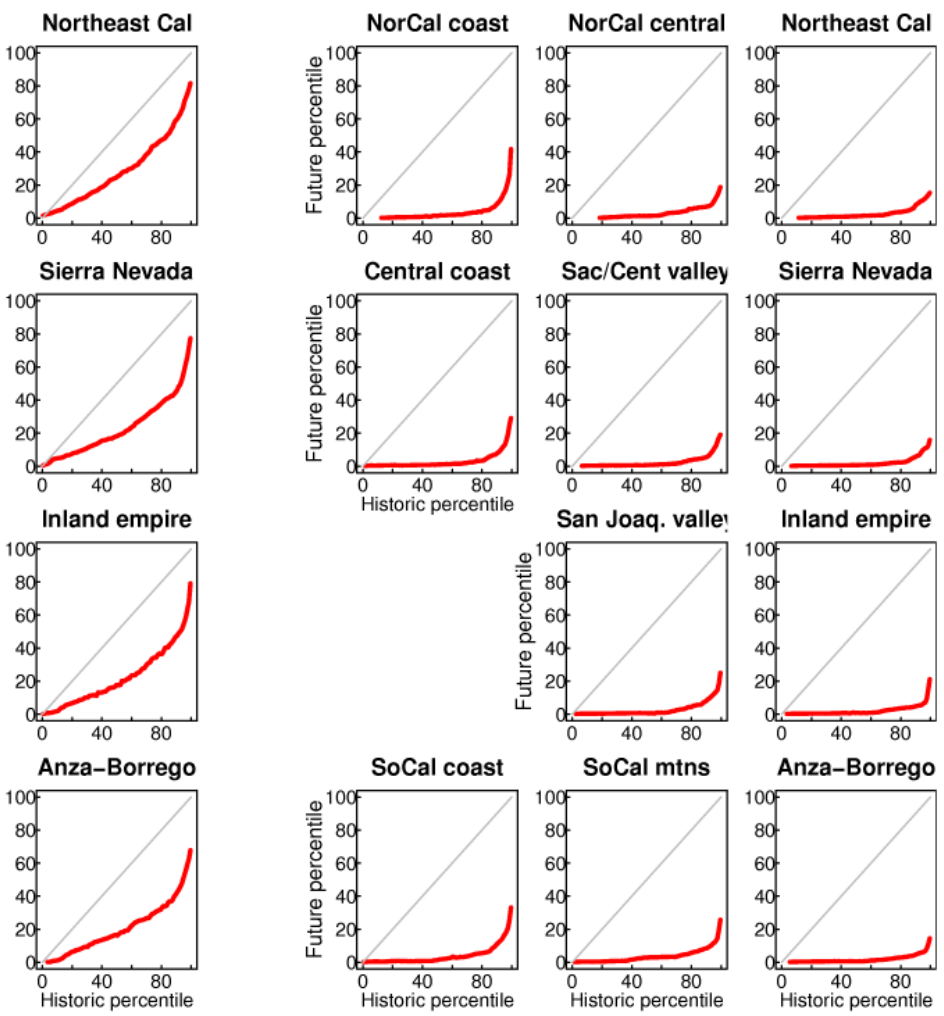

Figure 2. Correspondence between percentiles of monthly-averaged temperature in the historical period (x axis) and future period (y axis), for January (left) and July (right). For instance, the blue cross in panel a for the Sacramento/Central valley shows that the $50^{\text {th }}$ percentile temperature in the historical period will become the $17^{\text {th }}$ percentile value in the 2060s. The grey line shows what the result would be if there were no changes in the distributions. The regions are plotted in roughly geographic order (Northwest locations in the top left, etc.). The figure is made with monthly data 

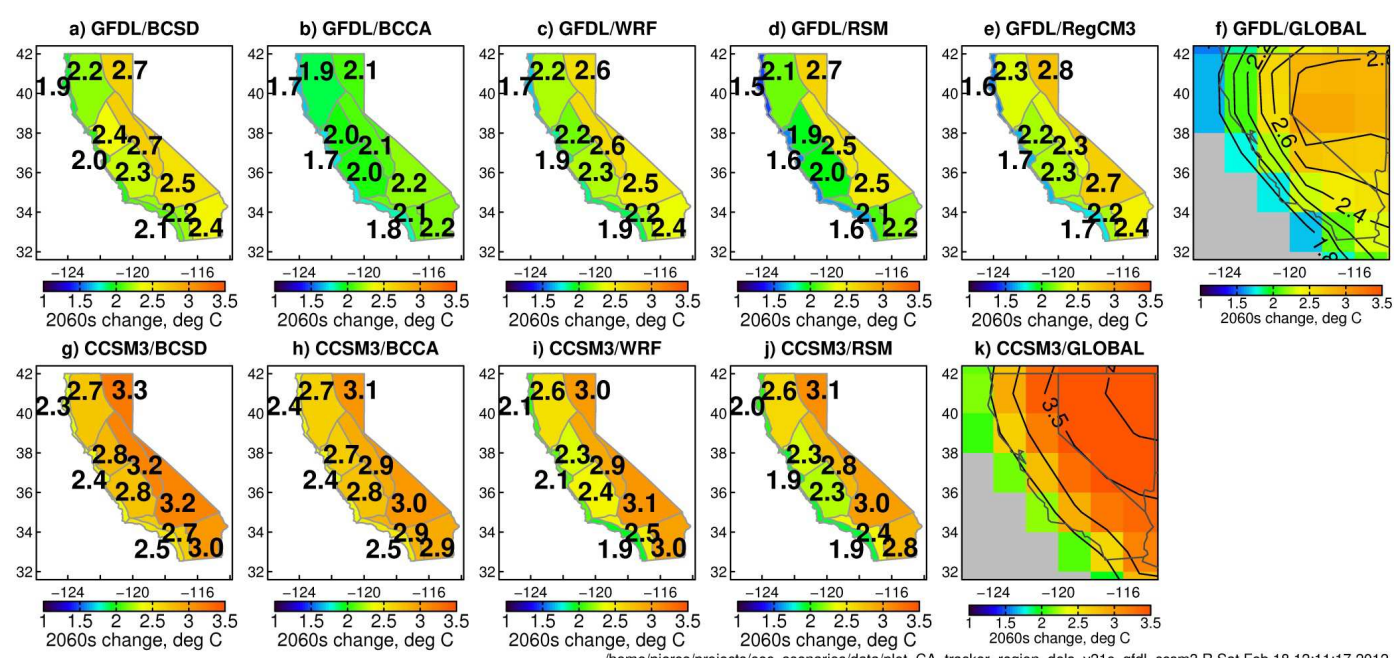

678 Figure 3. Yearly temperature change (C) (2060-2069 minus 1985-1994) from each downscaling 679 technique applied to the GFDL 2.1 global model (upper) and CCSM3 global model (lower). The 680 yearly temperature changes from the global models are shown in panels $\mathrm{f}$ and $\mathrm{k}$, for comparison. 

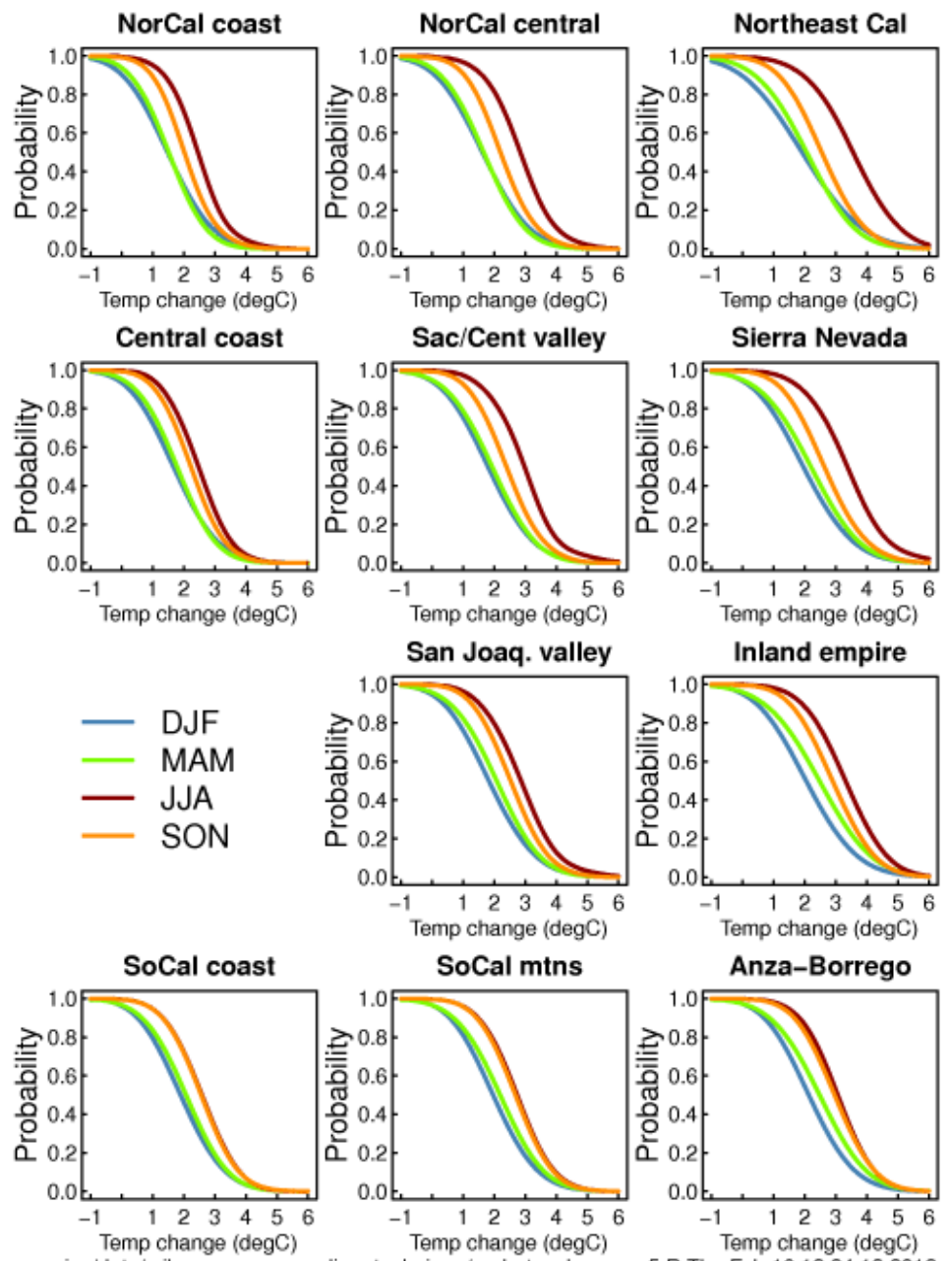

682 Figure 4. Probability of a temperature change of the indicated value or greater, by region and

683 season. The regions are plotted in roughly geographic order (Northwest locations in the top left,

684 etc.). Monthly data from all 45 runs is used to make the figure. 
a) Tair yearly

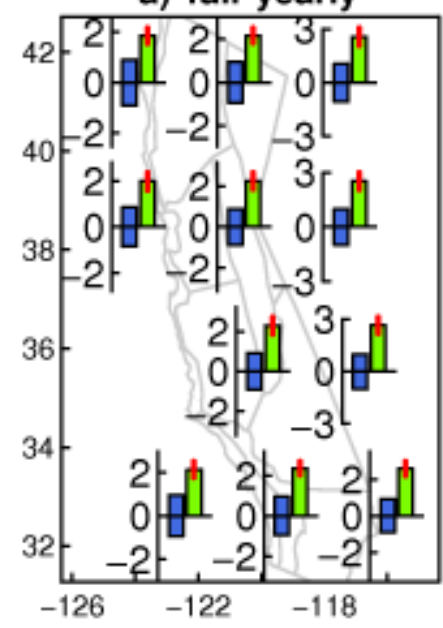

b) Tair DJF

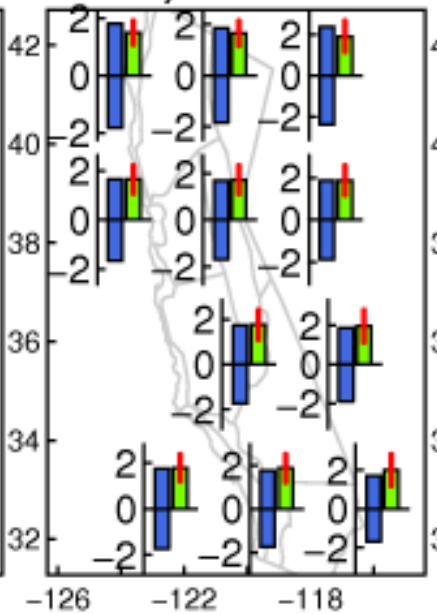

d) Tair JJA c) Tair MAM

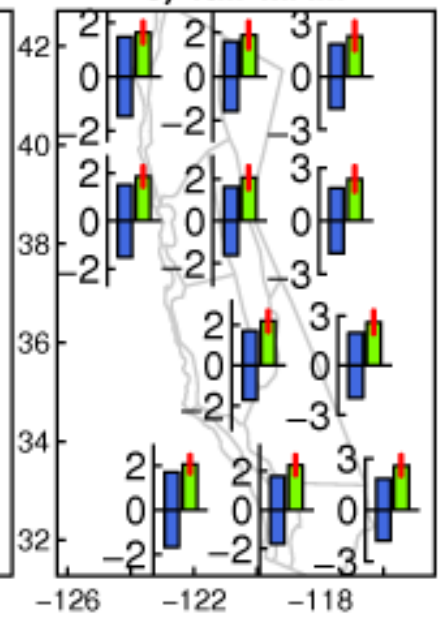

e) Tair SON

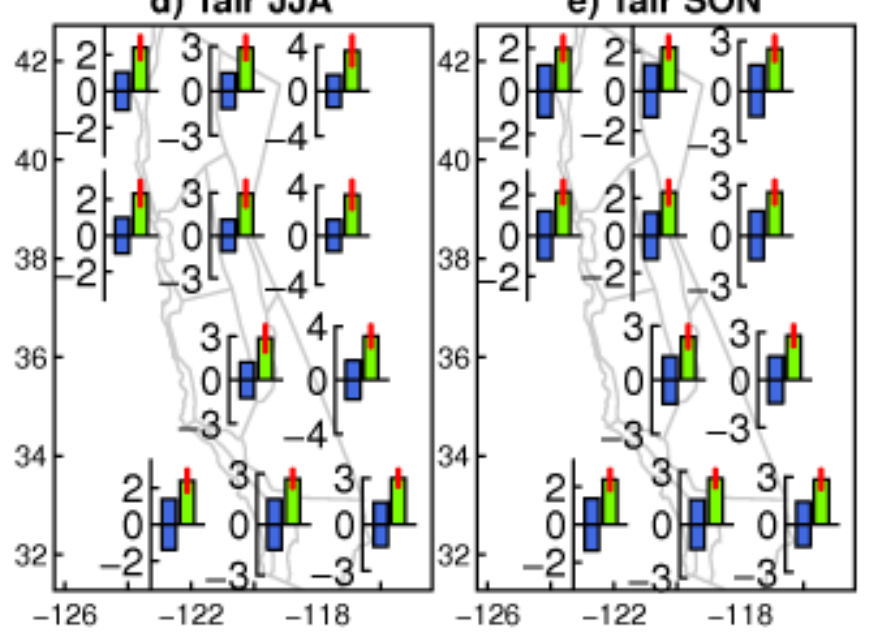

686 Figure 5. A comparison of the contribution of natural internal climate variability and model

687 uncertainty to yearly and seasonally averaged projected temperature changes by the 2060s. Blue

688 bars show the $90 \%$ confidence interval of natural internal climate variability in near surface air

689 temperature (C) estimated across all models. Green bars show the mean model warming projected

690 in the period 2060-69. The red line shows the $90 \%$ confidence interval in the projected warming

691 across models. Note that each inset plot has a different scale for the $\mathrm{Y}$ axis, in degrees C. Monthly

692 data from all 45 runs is used to make the figure. 
a) July daily Tmax (C)
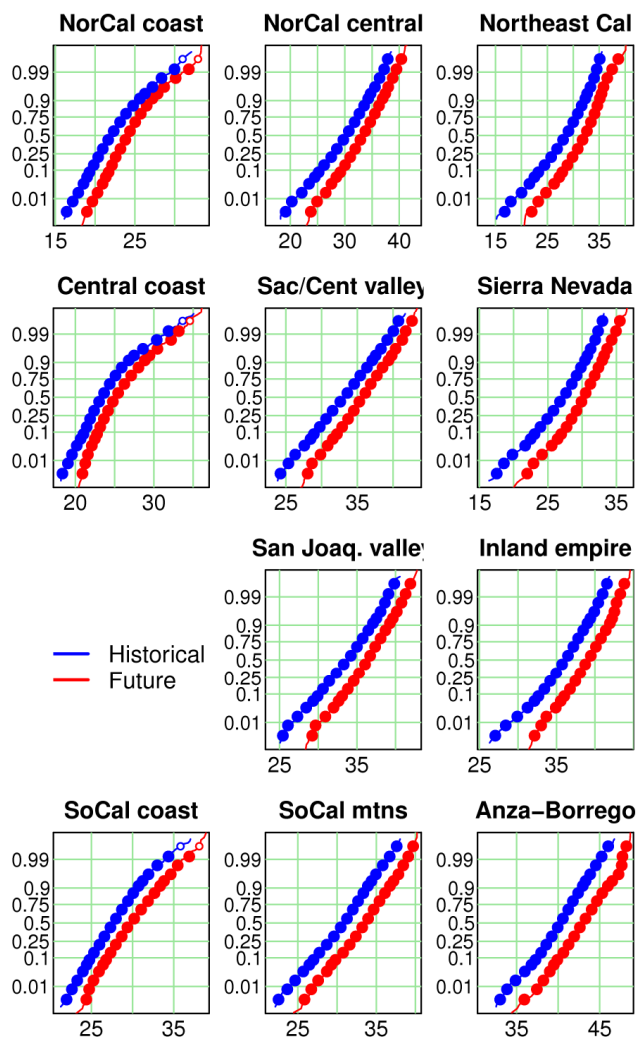

b) January daily $T \min (C)$
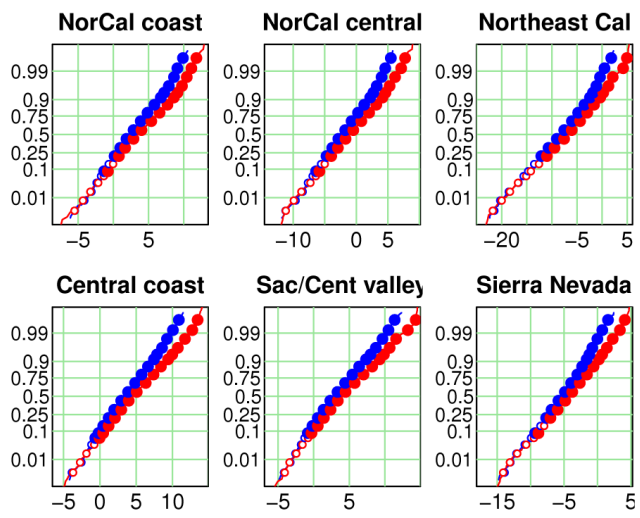

Sierra Nevada
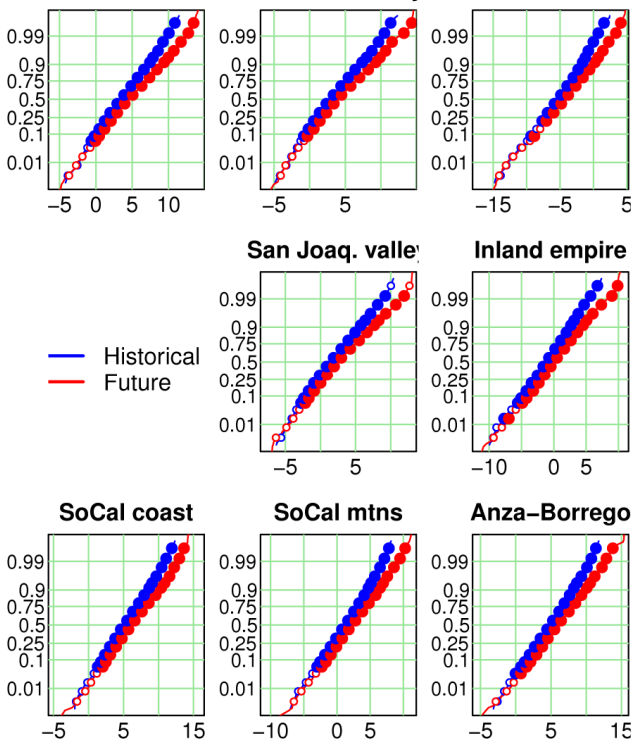

694 Figure 6. Cumulative distribution functions of July daily maximum temperature (left) and Januray

695 daily minimum temperature (right) across the regions (plotted roughly geographically). The $\mathrm{Y}$ axis

696 shows the probability (zero to one) of experiencing the indicated temperature or lower on any

697 particular day. Results from the historical run are in blue; the future run is in red. Large solid dots

698 show where the two curves are different at the 95\% significance level, evaluated using a bootstrap

699 technique. Open circles indicate statistically indistinguishable values. Data from the 9 runs with

700 daily data was used to make the figure. 

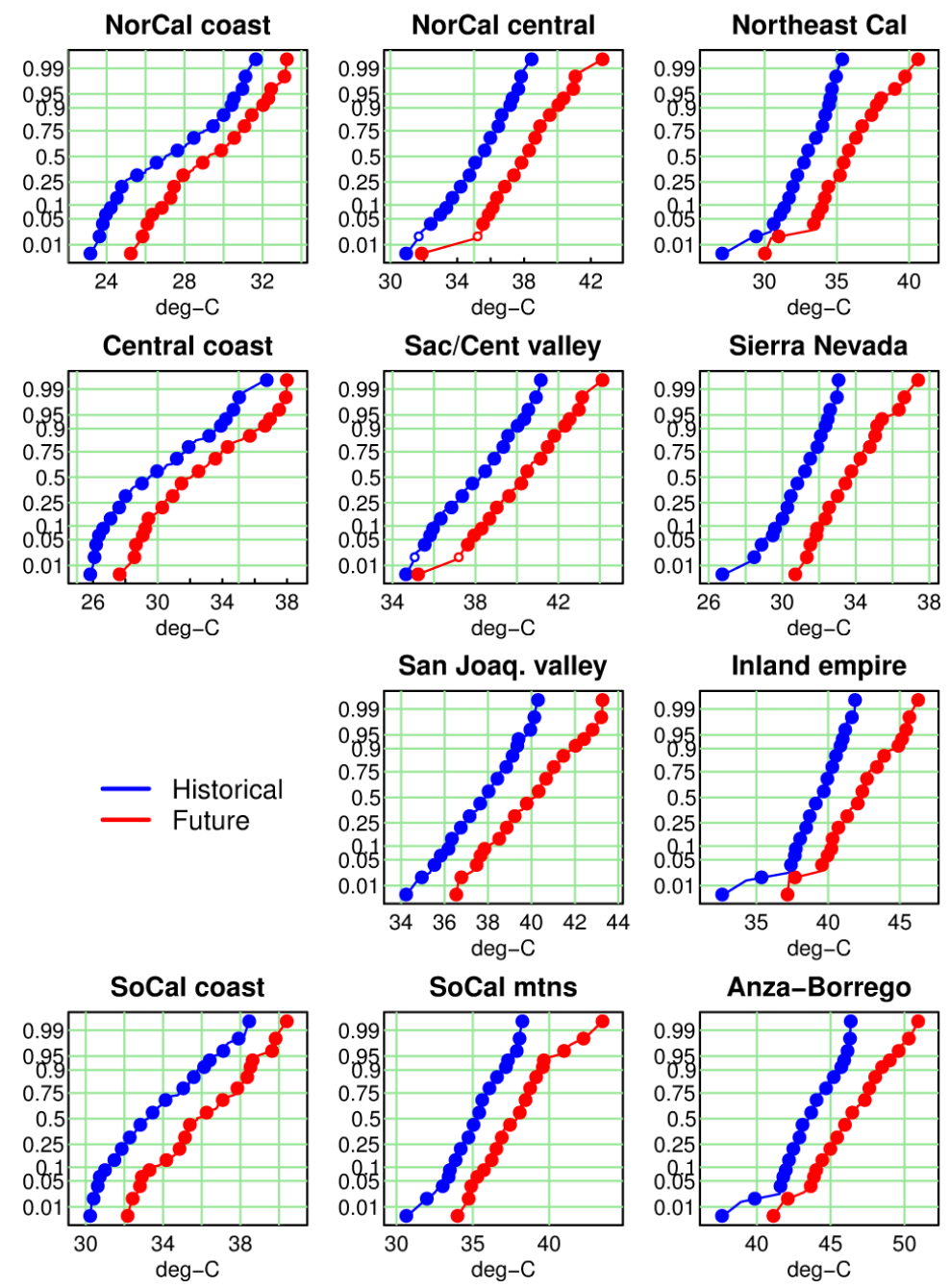

702 Figure 7. Cumulative distribution functions of the highest 3-day average temperature in the year.

703 The Y axis shows the probability (zero to one) of having the warmest 3 days in a year be the

704 indicated temperature or lower. Results from the historical run are in blue; the future run is in red.

705 Panels are plotted roughly geographically. Large solid dots show where the two curves are

706 different at the $95 \%$ significance level evaluated using a bootstrap technique. Data from the 9 runs

707 with daily data was used to make the figure. 

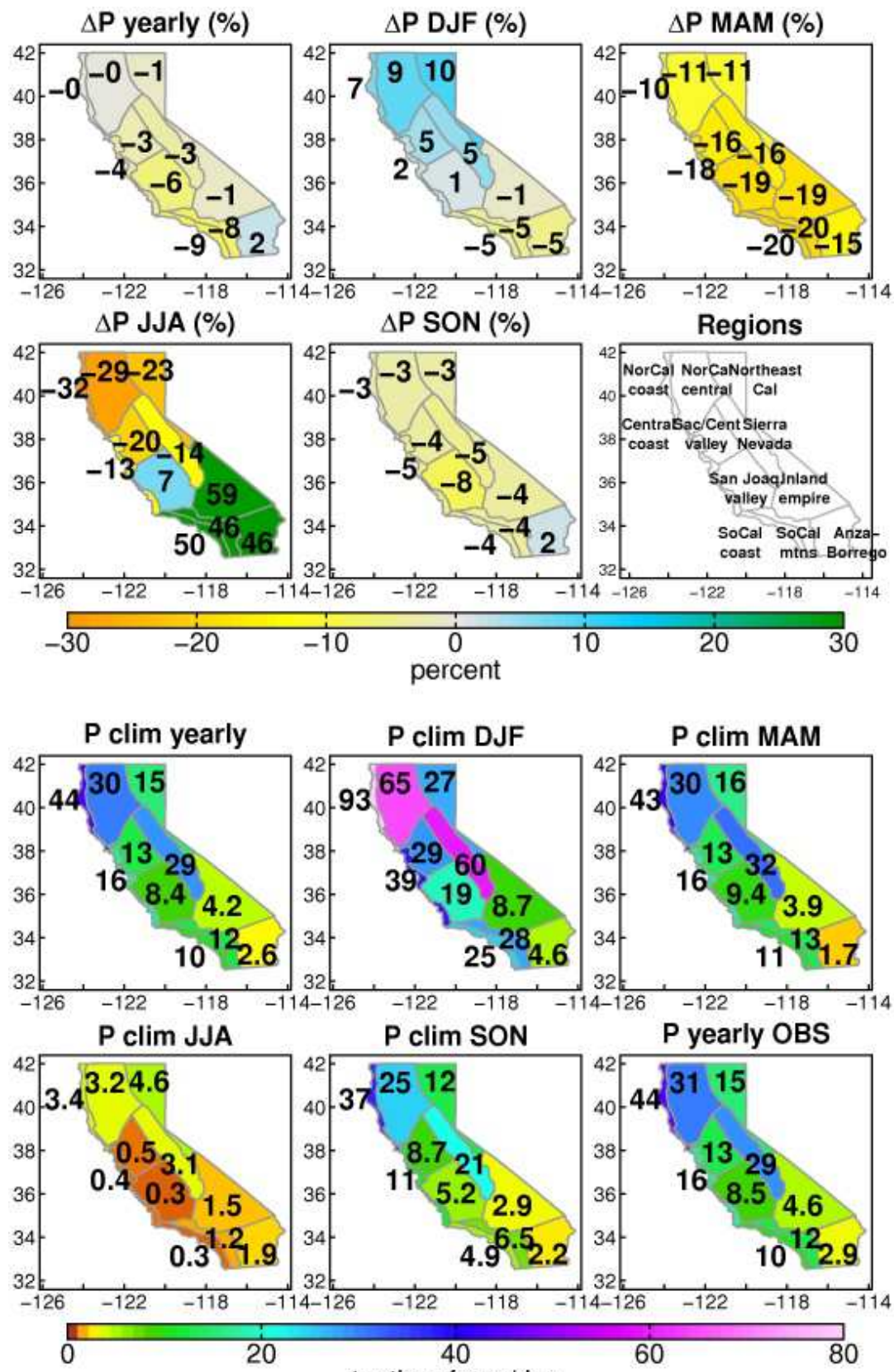

tenths of $\mathrm{mm} /$ day

709 Figure 8. Upper panels: Precipitation change (\%), mean over the period 2060-69 compared to

710 mean over the period 1985-94. Data from all models and downscaling techniques was averaged to

711 generate the values. Lower panels: model climatological precipitation (tenths of $\mathrm{mm} / \mathrm{day}$ ), and

712 annual average from observations for comparison (lower right). 
a) precip yearly

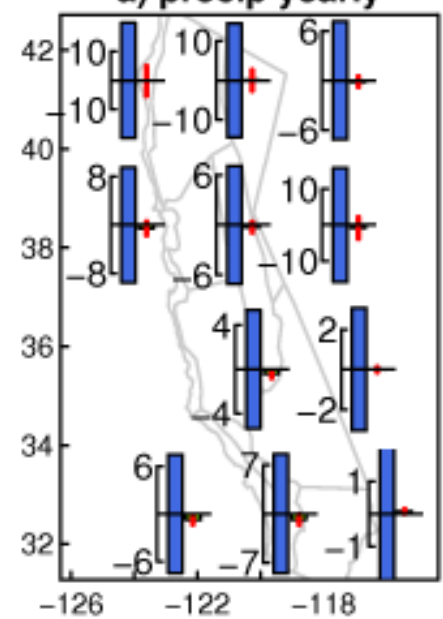

b) precip DJF

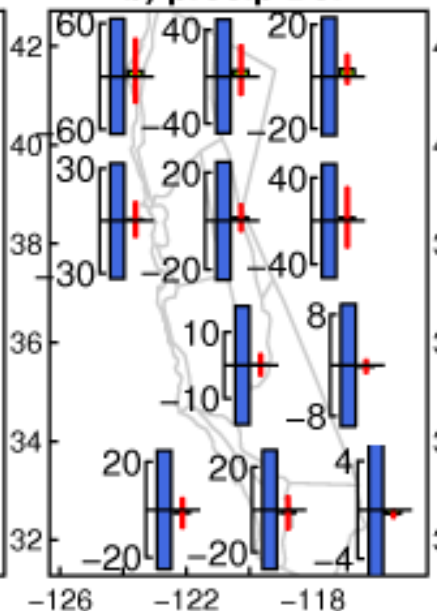

d) precip JJA c) precip MAM

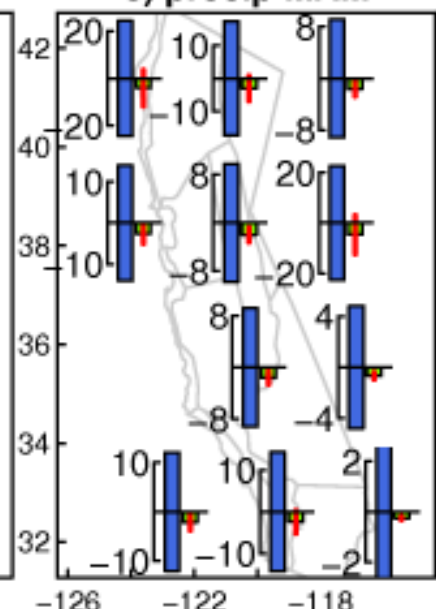

e) precip SON

714 Figure 9. A comparison of the contribution of natural internal climate variability and model

715 uncertainty to yearly and seasonally averaged precipitation changes. Blue bars show the $90 \%$

716 confidence interval of natural internal climate variability in seasonally averaged precipitation

717 (tenths of mm/day) estimated across all models, for the period 2060-69. Green bars show the mean

718 model precipitation change projected in the period 2060-69. The red line shows the 90\%

719 confidence interval in the projected precipitation change across models. Note that each inset plot

720 has a different scale for the $\mathrm{Y}$ axis. Monthly data from all 45 runs is used to make the figure. 

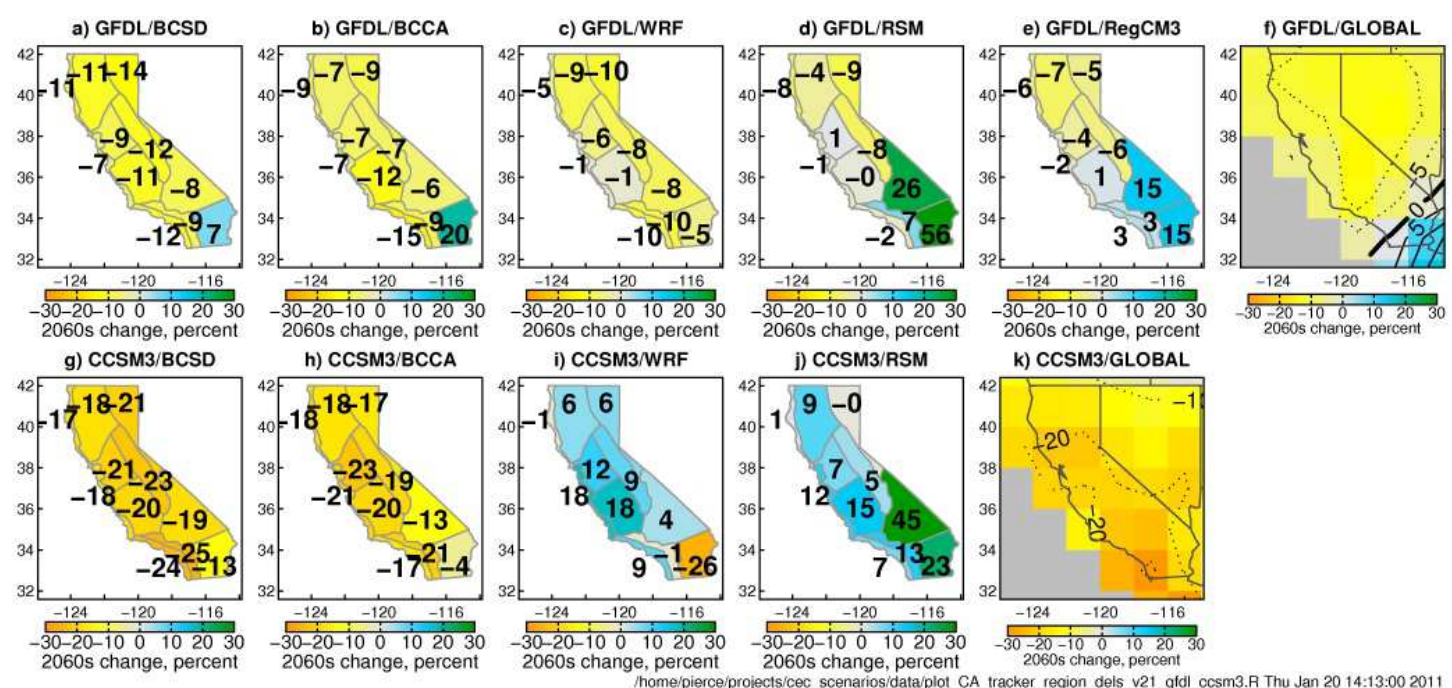

k) CCSM3/GLOBAL

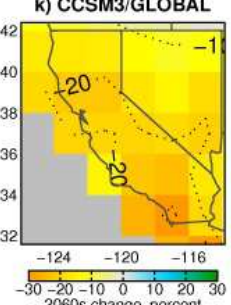

$20-100 \quad 10 \quad 20$

722 Figure 10. Yearly precipitation change (\%, 2060-2069 compared to 1985-1994) from each

723 downscaling technique applied to the GFDL 2.1 (top row) and CCSM3 (bottom row) global

724 models. The yearly precipitation changes from the global models are shown in panels $f$ and $k$, for

725 comparison. Since the effect of downscaling on the global model fields is being illustrated, only

726 one BCSD ensemble member is shown, the one corresponding to the illustrated global model and

727 used for the dynamical downscaling. 
a) CCSM3/BCSD

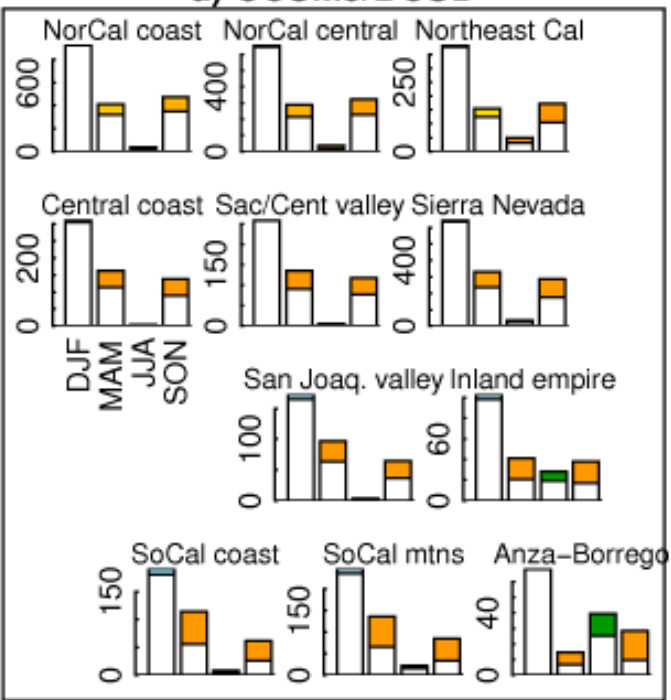

c) $\mathrm{CCSM} / \mathrm{WRF}$
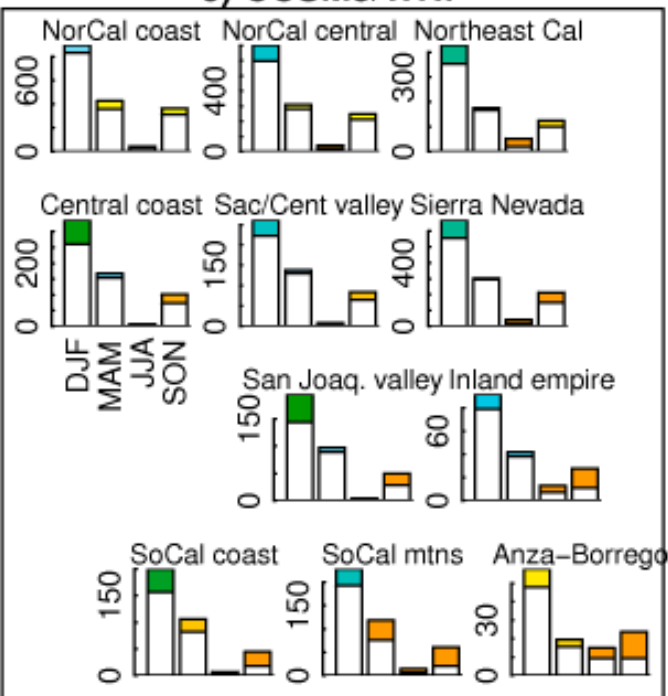

b) $\mathrm{CCSM} 3 / \mathrm{BCCA}$

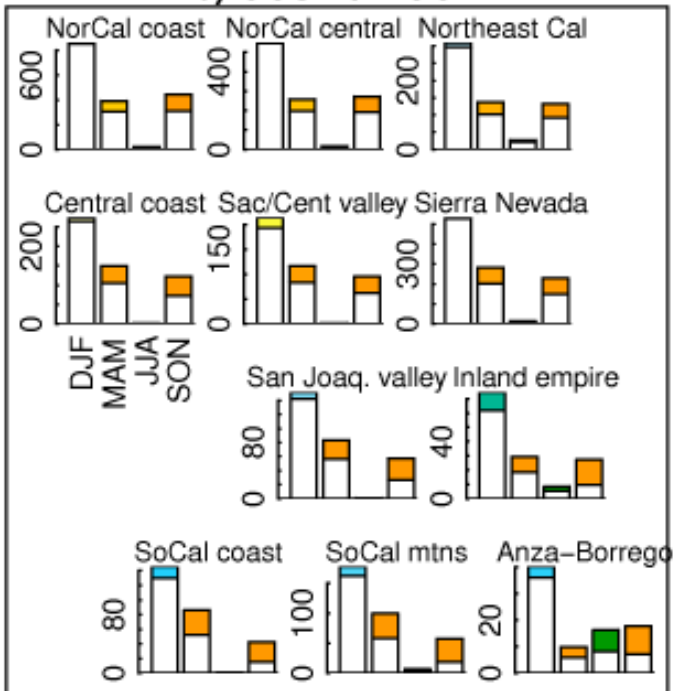

d) $\mathrm{CCSM} 3 / \mathrm{RSM}$
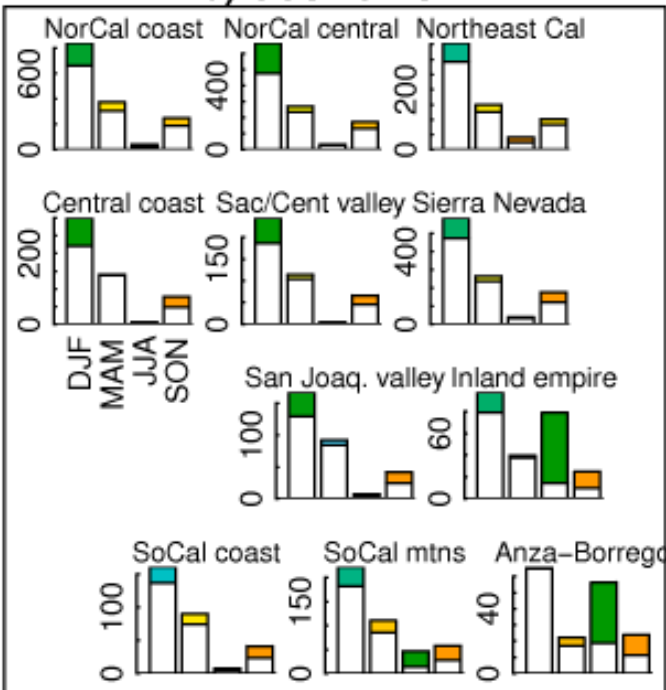

Figure 11. Changes in precipitation for the different downscaling methods applied to the CCSM3 global model. In each panel a-d, the subpanels show the precipitation changes by region, arranged roughly geographically. The bars show each region's seasonal precipitation (mm) in DJF, MAM,

732 JJA, and SON (left to right) in the future and historical periods. The difference between the future

733 and historical precipitation is colored, with the color determined by the percentage change using

734 the same scale as Fig. 10 (yellows/oranges show less precipitation, blue/green show more

735 precipitation). Note that every set of bars has a different $\mathrm{Y}$ axis, in $\mathrm{mm}$. 
GFDL

$\operatorname{CCSM} 3$
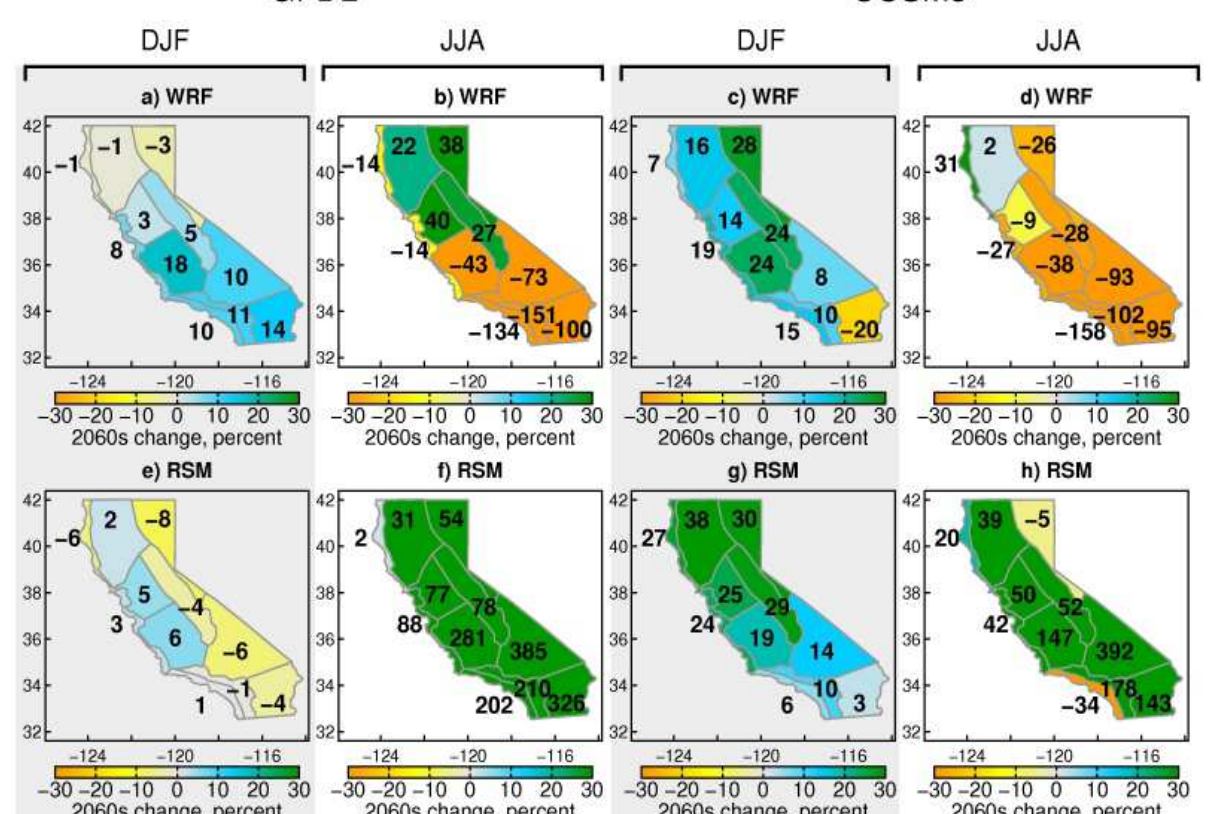

2060 s change, percent f) RSM g) RSM
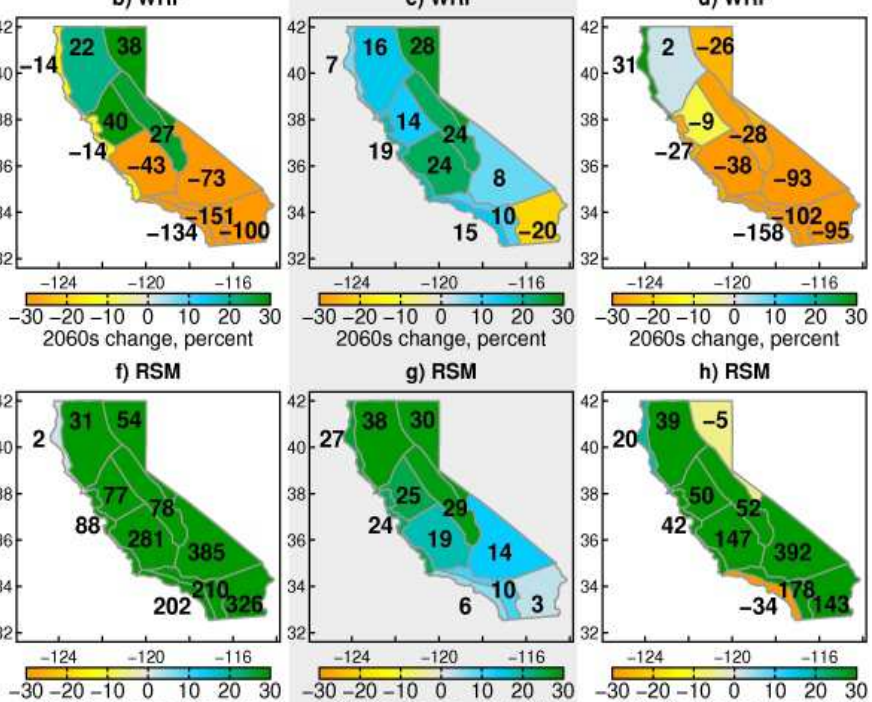

h) RSM
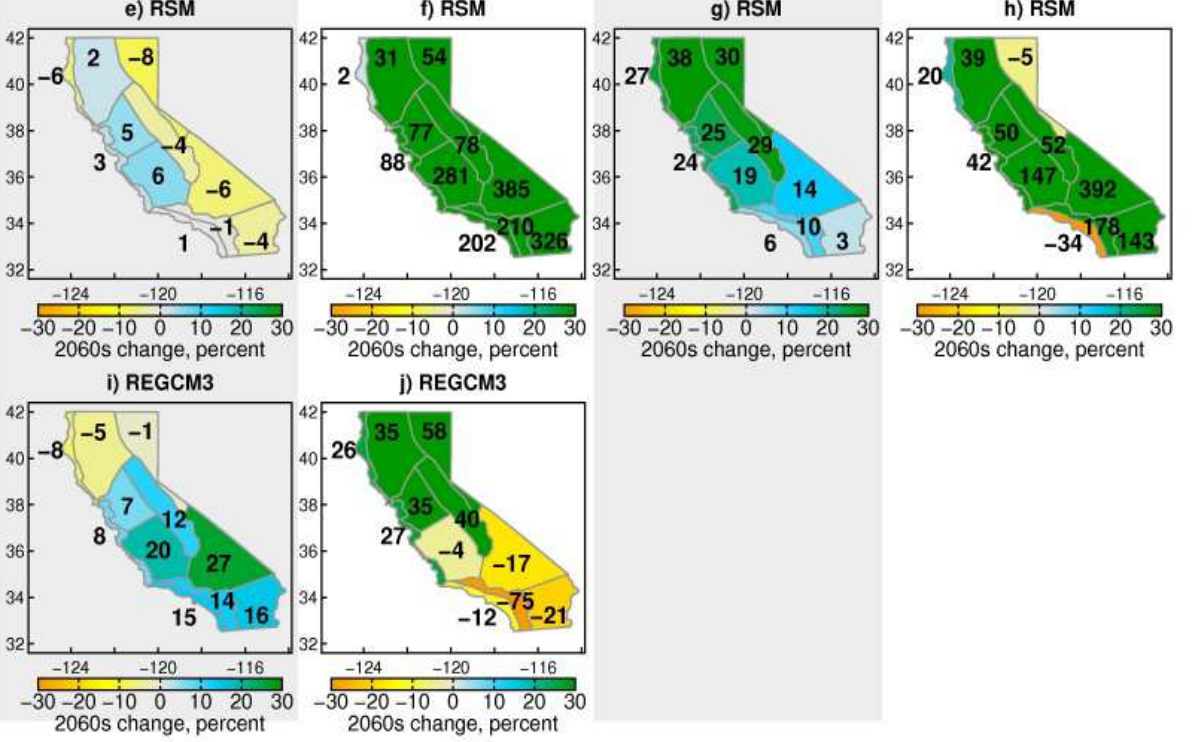

737 Figure 12. Difference (percentage points) between the change in seasonal precipitation projected

738 by the dynamically downscaled simulations and the change found in the original global model

739 (GFDL 2.1 or CCSM3, as labeled). Only winter (DJF) and summer (JJA) fields are shown. 

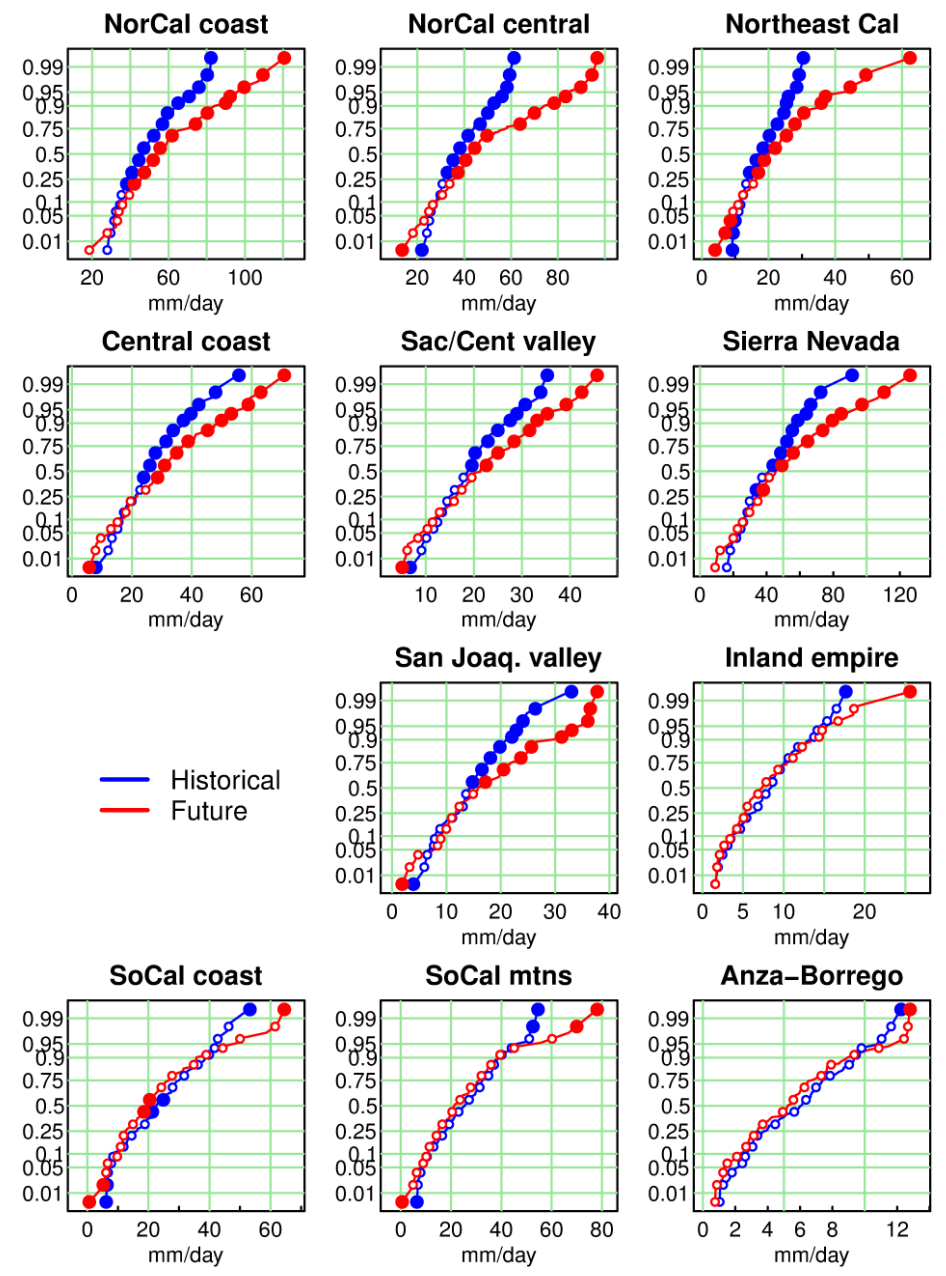

741 Figure 13. Cumulative distribution functions (CDFs) of the maximum 3-day mean precipitation in

742 a calendar year. Regions are plotted roughly geographically. Y axis is probability (0-1) of

743 experiencing the indicated average 3-day precipitation rate $(\mathrm{mm} /$ day), or lower. Large solid dots

744 show where the two curves are different at the $95 \%$ significance level, evaluated using a bootstrap

745 technique. Open circles indicate statistically indistinguishable values. Data from the 9 runs with

746 daily data was used to make the figure. 
748 Probabilistic estimates of future changes in

749 California temperature and precipitation using

750 statistical and dynamical downscaling

751 David W. Pierce ${ }^{1, *}$, Tapash Das ${ }^{1,6}$, Daniel R. Cayan ${ }^{1}$, Edwin P. Maurer ${ }^{2}$, Norman

752 Miller $^{3}$, Yan Bao ${ }^{3}$, M. Kanamitsu ${ }^{1}$, Kei Yoshimura ${ }^{1}$, Mark A. Snyder ${ }^{4}$, Lisa C.

753 Sloan $^{4}$, Guido Franco ${ }^{5}$, Mary Tyree $^{1}$

754 1. Descriptions of the Regional Climate Models (RCMs)

\subsection{Regional Climate Model version 3 (RegCM3)}

756 RegCM3 is a third-generation regional-scale climate model derived from the

757 National Center for Atmospheric Research-Pennsylvania State (NCAR-PSU)

758 MM5 mesoscale model (Pal et al. 2007). RegCM3 has the same dynamical core as

759 MM5, the CCM3 radiative transfer package, and the Biosphere-Atmosphere

760 Transfer Scheme (BATS) land surface model (Dickinson et al., 1986; Giorgi et al.,

761 2003). RegCM has been validated against observations of modern-day climate in

762 multiple domains, and does well in simulating the spatial and temporal climate

763 features of California (Snyder et al. 2002, Bell et al. 2004). For this study

764 RegCM3 was configured with the Holtslag boundary layer scheme (Holtslag et

765 al., 1990), Grell cumulus scheme (Grell, 1993) with the Fritsch and Chappell

766 closure scheme (Fritsch and Chappell, 1980), and the Zeng (1998) ocean flux

767 parameterization. The model domain is centered over California with a horizontal 768 resolution of $10 \mathrm{~km}$ and 18 levels in the vertical.

$769 \quad 1.2$ Weather Research and Forecasting model (WRF)

770 We use a version of NCAR WRF version 3 coupled to the community land

771 surface model version 3.5 (CLM3.5; Oleson et al. 2004), referred to as "WRF-

772 CLM3" in Miller et al. (2009). The combination has an advanced land surface

773 scheme with sub-grid representation for snow and vegetation, lateral hydrologic 
774 flow capability, and the potential for time-evolving plant functional types. The

775 WRF model is set up with $10 \mathrm{~km}$ horizontal resolution, and uses the Kain-Fritsch

776 convection parameterization for cumulus clouds (Kain and Fritsch 1993), the

777 Yonsei University (YSU) planetary boundary layer (PBL) scheme (Hong and Pan

778 1996), and the Medium Range Forecast Model turbulence closure scheme (Mellor

779 and Yamada 1982). The microphysics package used here is the WRF Single-

780 Moment 3-class (WSM3) scheme (Hong et al. 2004), and the Rapid Radiative

781 Transfer Model (RRTM) based on Mlawer et al. (1997) is used for describing

782 longwave radiation transfer within the atmosphere and to the surface, and the

783 shortwave scheme developed by Dudhia (1989). Dynamical downscaling using

784 WRF has been evaluated over the state of California (Caldwell et al. 2009), and

785 WRF coupled to CLM3.5 has been used to show that changes in vegetation can

786 have appreciable effects on local climate (Subin et al. 2011).

\subsection{Regional Spectral Model (RSM)}

788 The version of the regional spectral model (RSM) used here is a development of

789 the National Centers for Environmental Prediction (NCEP) global spectral model

790 (GSM). The original regional code has been modified to have greater flexibility

791 and increased efficiency (Kanamitsu et al., 2005). The RSM uses a two-

792 dimensional spectral decomposition, and is implemented with so-called "spectral

793 nudging", i.e., relaxation towards the low-frequency components of the global

794 simulation over the regional domain (Kanamaru and Kanamitsu 2007). The

795 configuration used here is similar to that used to generate the 10-km California

796 Reanalysis Downscaling (CaRD10) data set (Kanamitsu and Kanamuru, 2007). A

797 scale-selective bias correction (SSBC) was used during these runs (Kanamaru and

798 Kanamitsu 2007). The Noah land surface model with four soil layers was used,

799 and cloud water and cloudiness are implemented as prognostic variables (Tiedtke

800 1993; Iacobellis and Sommerville 2000).

\section{2. Statistical downscaling methods}

802 We use two different statistical downscaling techniques. Both operate on bias-

803 corrected GCM data; the bias correction (BC) procedure is described in section 
805 technique downscales monthly global model data.

\subsection{Bias Correction with Spatial Disaggregation (BCSD)}

807 BCSD (Wood et al. 2002, 2004) generates daily, fine-resolution $\left(1 / 8^{\circ} \times 1 / 8^{\circ}\right.$ in this

808 implementation) fields from monthly, bias-corrected GCM data by expressing

809 these coarse (GCM-scale) monthly values of average temperature and

810 precipitation as anomalies relative to a historical climatology. The monthly GCM

811 anomalies are interpolated onto the fine-scale grid, then applied, by offsetting (for

812 temperature) or scaling (for precipitation), to the long term mean at the fine scale.

813 This produces a fine scale monthly downscaled value. To generate daily

814 variability within each month an analogue month from the historical observations

815 is selected, with the selected month being the same month of the year as the data

816 being downscaled. The daily observed data for the analogue month on the fine-

817 scale grid is then offset (for temperature) or scaled (for precipitation) so that each

818 grid cell's monthly mean matches the monthly downscaled value. Since analogue

819 months from the historical period are used to generate the daily sequences, we do

820 not analyze BCSD-generated distributions of daily future climate variables. BCSD

821 downscaling is used, for example, by Hayhoe et al. (2004), Maurer (2007), and

822 Vicuna et al. (2007).

\subsection{Bias Correction with Constructed Analogues (BCCA)}

824 BCCA uses bias correction along with downscaling of daily GCM fields via

825 constructed analogues (Hidalgo et al., 2008; Maurer et al. 2010). BCCA is

826 therefore the CANA method described by Miller et al. (2009) along with a BC

827 step applied to the GCM temperature and precipitation fields. The constructed

828 analogue technique starts with a library of daily historical observations on a $1 / 8^{\circ} \mathrm{x}$

$8291 / 8^{\circ}$ grid. This fine scale data is coarsened to the GCM grid, and the 30 best

830 matches (analogues) between the GCM fields for that day (including in the library

831 observed days within a \pm 45 day window of the target date) and the coarsened

832 observations are computed. The 30 analogues are combined, using the strength of

833 their correspondence to the GCM grid as weights, into a GCM-sclae constructed 
834 analogue. The same linear combination is then applied to the fine scale observed

835 data to obtain the final downscaled data for a day.

\section{3. Bias correction procedure}

837 The output of the GCMs was bias corrected to observations (Maurer et al. 2002)

838 before statistical downscaling, while the output of the dynamical RCMs was bias

839 corrected after being generated. In general, before bias correction the RCMs tend

840 to display 10-20\% drier than observed conditions in the Northern part of the state

841 in winter, $20-50 \%$ too wet conditions in the inland desert regions in winter, 10-

$84220 \%$ wetter conditions than observed in the Northern part of the state in spring,

843 and an overall warm bias of 0.1-2.0 $\mathrm{C}$ throughout the year.

844 BCSD starts with monthly GCM data, which we bias correct using the quantile845 mapping technique (Panofsky and Brier, 1968), described in Maurer (2007), based

846 on Wood et al. $(2002,2004)$. The mapping parameters are determined for each

847 month by comparing the model results to the observations over the

848 model/observations overlap period 1950-1999, and then are applied to the future

849 period. The assumption is that the biases are unchanged in the future (cf. Liang et

850 al. 2008). For bias correcting GCM output, Wood et al. (2004) suggest as long a

851 historical period as possible be used to characterize monthly GCM biases, with

852 ranges for robust error correction from 20-50 years (or longer). For temperature,

853 the linear trend from the GCM output (interpolated to the fine scale grid) was

854 removed at each point before the BC procedure was applied, and then added back

855 in afterwards. The reason for this is explained by Wood et al. (2004): as

856 temperatures rise in the future they are found more frequently outside the historic

857 range, requiring excessive extrapolation during the quantile mapping.

858 Precipitation, with typically much greater interannual variability than temperature,

859 does not generally experience trends that exhibit this problem during remapping,

860 so the trend removal and replacement was not applied. In theory, this procedure

861 has the advantage that the final result preserves the original trend in the global

862 model, but the disadvantage that the resulting trend is essentially that of the

863 interpolated global model. In practice, the application of bias correction can still

864 modify the original global model trends for reasons explained below. 
865 The BCCA and RCM data are daily. We bias correct the daily data using a similar

866 quantile mapping technique, described in Maurer et al. (2010). The historical

867 period used for the monthly BCCA downscaling was the 50-yr span 1950-1999,

868 but only the 10-yr period 1984-1995 is available for the RCM data. When bias

869 correcting daily (instead of monthly) data, 10 years is adequate, as 10 years of

870 daily information ( $\sim 3652$ time steps) provides considerably more samples than 50

871 years of monthly information (600 time steps) (Maurer et al., manuscript in

872 preparation; see also Chen et al. 2011).

873 In contrast to BCSD, the global trend was not removed and then reapplied for the

874 BCCA and RCM data, since the motivation for trend removal and replacement

875 described above is not as strong for daily data. For example, since a large portion

876 of the trend in daily temperatures is due to more frequent warm temperatures (as

877 opposed to relatively few record hot temperatures) (Dettinger et al. 2004), which

878 are represented in the historic period, the trend removal and replacement

879 procedure is less necessary. This also means that the trend in these data sets is free

880 to differ from the GCM trend. Since the basic assumption of downscaling is that it

881 adds regionalized information to the global signal, this is a desirable

882 characteristic.

883 However, the bias correction itself can modify the global trend (Hagemann et al.

884 2011). Table SM1 illustrates this for July average daily temperature at one grid

885 point. Bias correction modifies the variance of the GCM output, since GCM

886 simulations inevitably contain biases in variance, skew, and higher moments. The

887 historical mapping is applied to future projections, so this process changes the

888 statistical properties of the GCM projections. This table shows that when bias

889 correction increases the standard deviation of the monthly data, then the low-

890 frequency trend increases as well; when BC decreases the standard deviation, the

891 trend decreases. In essence, the procedure assumes that errors in the amplitude of

892 variability apply equally on all timescales, from daily to the secular trend.

893 Whether the trend modification is appropriate given GCM errors in simulating

894 variability or if the raw simulated trend should be preserved through the

895 downscaling procedure is an open question. 
897 The procedure described in the main text section 3.1.2 underestimates the value of

898 natural internal climate variability since it is based the spread around the 10-yr

899 average during the 2060's, but the 10-yr average itself will be affected by low-

900 frequency natural internal climate variability. The size of this effect can be

901 estimated from the historical record, assuming that future changes in the spectral

902 structure of natural variability will be modest.

903 Using the technique described in Appendix A of Barnett \& Pierce (2008)

904 (transforming an observed time series to frequency space, randomizing the phases,

905 and transforming back while taking sampling uncertainty in the estimate of the

906 spectral amplitudes into account), we constructed 200 random time series for each

907 variable (T, P) and each California region. Observed time series were computed

908 from Hamlet and Lettenmaier (2005). Each random time series, by construction,

909 has a mean and spectrum that is indistinguishable from observations (within

910 sampling uncertainty). We then used the 200 random time series to calculate the

911 natural variability as done in section 3.1.2 (in a 10-yr chunk) and compared it to

912 the variability directly calculated from the full time series.

913 For temperature, the true $90 \%$ confidence interval was $6-20 \%$ wider than

914 calculated as in the manuscript; for precipitation, the true $90 \%$ C.I. was 5-25\%

915 wider (Table SM2). This overstates the error in for temperature, since all

916 California regions show a strong warming over the observed time period that has

917 been shown to be anthropogenic in origin (e.g., Bonfils et al., 2008). Using a

918 simple linear detrending for temperature and recomputing, the true C.I. for

919 temperature was 6-14\% wider than indicated by the method used in the

920 manuscript. Figures 5 and 9 in the main text have been corrected to show this

921 wider range for natural internal variability (the blue bars).

\section{Supplemental Material References}

923 Barnett TB, Pierce DW (2008) When will Lake Mead go dry? Water Resources Res 44:W03201

924 doi:10.1029/2007WR006704 
926 C, Wood AW, Mirin A, Nozawa T (2008) Detection and attribution of temperature changes in the

927 mountainous western United States. J Climate 21:6404-6424

928 Chen C, Haerter JO, Hagemann S, Piani C (2011) On the contribution of statistical bias correction 929 to the uncertainty in the projected hydrological cycle. Geophys Res Lett 38:L20403

930 Dettinger MD, Cayan DR, Meyer M, Jeton AE (2004) Simulated hydrologic responses to climate

931 variations and change in the Merced, Carson, and American River basins, Sierra Nevada,

932 California, 1900-2099. Clim Change 62:283-317.

933 Dickinson RE, Kennedy PJ, Henderson-Sellers A, Wilson M (1986) Biosphere-atmosphere

934 transfer scheme (BATS) for the NCAR Community Climate Model, Tech. Rep. NCAR/TN-

935 275+STR, National Center for Atmospheric Research

936 Dudhia J (1989) Numerical study of convection observed during the winter monsoon experiment

937 using a mesoscale two-dimensional model. J Atmo Sci 46:3077-3107

938 Fritsch JM, Chappell CF (1980) Numerical prediction of convectively driven mesoscale pressure

939 systems. part I: Convective parameterization. J Atmos Sci 37:1722-1733

940 Giorgi F, Bi XQ, Qian Y (2003) Indirect vs. direct effects of anthropogenic sulfate on the climate 941 of east asia as simulated with a regional coupled climate-chemistry/aerosol model. Clim Change $942 \quad 58: 345-376$

943 Grell G (1993) Prognostic evaluation of assumptions used by cumulus parameterizations. Mon

944 Wea Rev 121:764-787

945 Hagemann S, C Chen, JO Haerter, J Heinke, D Gerten, C Piani (2011) Impact of a Statistical Bias

946 Correction on the Projected Hydrological Changes Obtained from Three GCMs and Two

947 Hydrology Models. J Hydromet 12:556-578

948 Hamlet AF, Lettenmaier DP (2005) Production of temporally consistent gridded precipitation and

949 temperature fields for the continental United States. J Hydromet 6:330-336

950 Hidalgo HG, Dettinger MD, Cayan DR (2008) Downscaling with Constructed Analogues: Daily

951 precipitation and temperature fields over the Unites States. California Energy Commission

952 technical report CEC-500-2007-123. 48 pp.

953 Holtslag, AAM, de Bruijn EIF, Pan H-L (1990) A high resolution air mass transformation model

954 for short-range weather forecasting. Mon Wea Rev 118:1561-1575

955 Hong SY, Pan HL (1996) Nonlocal boundary layer vertical diffusion in a Medium-Range Forecast

956 Model. Mon Wea Rev 124:2322-2339 
957 Hong SY, Dudhia J, Chen SH (2004) A revised approach to ice microphysical processes for the

958 bulk parameterization of clouds and precipitation. Mon Wea Rev 132:103-120

959 Iacobellis SF, Somerville RCJ (2000) Implications of microphysics for cloud-radiation

960 parameterizations: Lessons from TOGA COARE. J Atmos Sci 57:161-183

961 Kain JS and Fritsch JM (1993) Convective parameterization for mesoscale models: The Kain-

962 Fritsch scheme. Meteor Monogr No. 24, Amer. Meteor. Soc., 165-170.

963 Kanamaru H, Kanamitsu M (2007) Scale-selective bias correction in a downscaling of global

964 analysis using a regional model. Mon Wea Rev 135:334-350

965 Kanamitsu M, Kanamaru H, Cui Y, Juang H (2005) Parallel implementation of the regional

966 spectral atmospheric model. California Energy Commission technical report CEC-500-2005-014.

967 www.energy.ca.gov/2005publications/CEC-500-2005-014/CEC-500-2005-014.

968 Kanamitsu M, Kanamaru H (2007) Fifty-seven-year California Reanalysis Downscaling at $10 \mathrm{~km}$

969 (CaRD10). Part I: System detail and validation with observations. J Clim 20:5553-5571

970 Liang XZ, Kunkel KE, Meehl GA, Jones RG, Wang JXL (2008) Regional climate models

971 downscaling analysis of general circulation models present climate biases propagation into future

972 change projections. Geophys Res Lett 35 doi:10.1029/2007GL032849

973 Maurer EP, Wood AW, Adam JC (2002) A long-term hydrologically based dataset of land surface

974 fluxes and states for the conterminous United States. J Clim 15:3237-51

975 Maurer EP, Brekke L, Pruitt T, Duffy PB (2007) Fine-resolution climate change projections

976 enhance regional climate change impact studies, Eos, Transactions, American Geophysical Union,

977 88:504, doi:10.1029/2007EO470006

978 Maurer EP, Hidalgo HG, Das T, Dettinger MD, Cayan DR (2010) The utility of daily large-scale

979 climate data in the assessment of climate change impacts on daily streamflow in California.

980 Hydrol. Earth Syst. Sci., 14:1125-1138, doi:10.5194/hess-14-1125-2010

981 Mellor GL, Yamada T (1982) Development of a turbulence closure-model for geophysical fluid

982 problems. Rev Geophys 20:851-875

983 Miller NL, Jin J, Schlegel NJ, Snyder MA et al. (2009) An analysis of simulated California climate 984 using multiple dynamical and statistical techniques. California Energy Commission report CEC-

985 500-2009-017-F, August, 2009. 47 pp.

986 Mlawer EJ, Taubman SJ, Brown PD, Iacono MJ, Clough SA (1997) Radiative transfer for

987 inhomogeneous atmospheres: RRTM, a validated correlated-k model for the longwave. J Geophys

988 Res Atmos 102:16663-16682 
989 Oleson KW, Dai Y, Bonan G, Bosilovichm M et al. (2004) Technical description of the

990 community land model (CLM). NCAR Tech. note NCAR/TN-461+STR. 186 pp.

991 Pal JS, Giorgi F, Bi XQ, Elguindi N et al. (2007) Regional climate modeling for the developing 992 world - The ICTP RegCM3 and RegCNET. Bull Amer Met Soc 88:1395

993 Panofsky HA. Brier GW (1968) Some Applications of Statistics to Meteorology, The Pennsylvania State 994 University, University Park, PA, USA, 224 pp.

995 Subin ZM, Riley WJ, Jin J, Christianson DS, Torn MS, Kueppers LM (2011) Ecosystem feedbacks

996 to climate change in California: Development, testing, and analysis using a coupled regional

997 atmosphere and land-surface model (WRF3-CLM3.5). Earth Interactions. 15: 1-38. doi:

$998 \quad 10.1175 / 2010 \mathrm{EI} 331.1$

999 Tiedtke M (1993) Representation of clouds in large-scale models. Mon Wea Rev 121:3040-3061

1000 Wood AW, Maurer EP, Kumar A, Lettenmaier DP (2002) Long-range experimental hydrologic

1001 forecasting for the eastern United States. J Geophys Res Atmos 107, doi:10.1029/2001jd000659

1002 Wood AW, Leung LR, Sridhar V, Lettenmaier DP (2004) Hydrologic implications of dynamical

1003 and statistical approaches to downscaling climate model outputs. Clim Change 62:189-216

1004 Zeng XB, Zhao M, Dickinson RE (1998) Intercomparison of bulk aerodynamic algorithms for the

1005 computation of sea surface fluxes using TOGA COARE and TAO data. J Clim 11:2628-2644 
1006 Table SM1

\begin{tabular}{|c|c|c|c|c|}
\hline Statistic & NCAR & CNRM & NCAR & GFDL \\
\hline & CCSM3 & CM3 & PCM1 & CM2.1 \\
\hline$\sigma$ pre bias correction & 0.84 & 0.66 & 0.49 & 0.73 \\
\hline$\sigma$ post bias correction & 0.67 & 0.85 & 0.50 & 0.60 \\
\hline$\Delta \mathrm{T}$ pre bias correction & 2.7 & 1.7 & 1.3 & 2.3 \\
\hline $\begin{array}{l}\Delta \mathrm{T} \text { post bias } \\
\text { correction }\end{array}$ & 2.2 & 2.3 & 1.3 & 1.9 \\
\hline
\end{tabular}

1007

1008 Table SM1. An example of the effect of bias correction on the standard deviation

1009 ( $\sigma$ ) of average daily July temperature (for a future period of 2040-2069) on the

1010 projected changes in temperature $(\Delta \mathrm{T})$ between the future period and a historic

1011 baseline of 1950-1999 for a single grid point located at latitude 39, longitude -121, 1012 over northern California. 


\begin{tabular}{lll}
\hline Region & a) T error & $\begin{array}{l}\text { b) T error } \\
\text { (detrended) }\end{array}$
\end{tabular}

\begin{tabular}{llll}
\hline S. California coast & $20 \%$ & $13 \%$ & $9 \%$ \\
\hline $\begin{array}{l}\text { Anza-Borrego } \\
\text { San Joaquin } \\
\text { valley }\end{array}$ & $8 \%$ & $6 \%$ & $25 \%$ \\
\hline $\begin{array}{l}\text { Sierra Nevada } \\
\text { Northeast }\end{array}$ & $7 \%$ & $8 \%$ & $9 \%$ \\
$\begin{array}{l}\text { California } \\
\text { N. California } \\
\text { coast }\end{array}$ & $18 \%$ & $7 \%$ & $5 \%$ \\
\hline $\begin{array}{l}\text { Central N. } \\
\text { California }\end{array}$ & $10 \%$ & $14 \%$ & $9 \%$ \\
\hline $\begin{array}{l}\text { Central coast } \\
\text { S. California }\end{array}$ & $19 \%$ & $10 \%$ & $6 \%$ \\
\hline $\begin{array}{l}\text { Mtns. } \\
\text { Inland Empire }\end{array}$ & $12 \%$ & $8 \%$ & $5 \%$ \\
\hline $\begin{array}{l}\text { Sac/Central } \\
\text { Valley }\end{array}$ & $19 \%$ & $7 \%$ & $10 \%$ \\
\hline & & $6 \%$ & $9 \%$ \\
\hline
\end{tabular}

1015 Table SM2. Estimated error in the 90\% confidence interval of natural internal

1016 climate variability obtained when taking the average with respect to a 10-year

1017 period rather than using the entire period of record. Values are based on

1018 observations over the period 1915-2004. Column a) temperature; b) temperature,

1019 but detrending the temperature record first to remove anthropogenic warming; c)

1020 precipitation. See supplemental material text (section 4) for details. 